\title{
Dietary Antioxidants: From Micronutrients and Phytochemicals to Enzymes - Preventive Effects on Early Atherosclerosis and Obesity
}

\author{
Sylvie Gaillet ${ }^{1}$, Dominique Lacan ${ }^{2}$ and Jean-Max Rouanet ${ }^{1}$ \\ IUMR 204 NUTRIPASS, \\ Université Montpellier 2, Montpellier, \\ ${ }^{2}$ BIONOV S.A.R.L., Montpellier,
}

France

\section{Introduction}

Development of atherosclerosis is thought to be closely dependent upon increased oxidative stress, that is, an imbalance between reactive oxygen species (ROS).

Elsewhere, high-fat diets and sedentary lifestyles are important risk factors for obesity, which is a key feature of metabolic syndrome and which greatly predisposes individuals to liver diseases, cardiovascular disease (CVD), type 2 diabetes, dyslipidemia, hypertension, and numerous cancers and is associated with markedly diminished life expectancy.

Today, due to oxidative stress, the postulated involvement of lipid peroxidation in atherogenesis and obesity invoked intensive interest in the use of antioxidant nutritional supplements. Epidemiological evidence suggests that intake of some vitamins, minerals, and other food constituents may help to protect against heart disease, obesity, cancer and the aging process and that antioxidants may have a protective effect, in either preventing these diseases or lessening the severity of the diseases upon their onset.

Many compounds, from natural sources, newly synthesised derivatives of these compounds, and common drugs, were tested for their potency to inhibit the peroxidation of plasma lipids induced by different oxidants in vitro to reduce the plaque formation in animal models in vivo and to reduce the morbidity and mortality in human subjects, in clinical trials. Indeed, mortality from cardiovascular disease is the leading cause of death in the industrialised world. Diet is believed to play a major role in the development of this disease, and much research is being focused on identifying ways to prevent it through changes in dietary habits. A potentially important clinical corollary of the atherosclerosis oxidation theory is that inhibition of LDL oxidation may also inhibit atherosclerosis independent of lowering plasma cholesterol concentrations.

Moreover, a close correlation has been found between increased oxidative stress in accumulated fat and the pathogenic mechanism of obesity and obesity-associated metabolic 
syndrome. It has been reported that obesity is a strong independent predictor of systemic oxidative stress, suggesting that obesity is associated with a state of excess oxidative stress. This may be the source of several metabolic dysfunctions such as inflammation, hypertension, and impaired glucose intake in muscle and fat, which are highly related to obesity. Oxidative stress could be a potential link between fat accumulation and obesityrelated morbidity such as diabetes and cardiovascular diseases. Indeed, this pathology can contribute to an increased susceptibility to ROS.

Dietary factors are thought to play a key role in the regulation of the oxidant status. Thus, it is essential to develop and utilise effective and natural antioxidants so that they can protect the human body from free radicals and retard the progress of many chronic diseases. The importance of dietary antioxidants in human health is clear and some epidemiological studies showed the potential health benefits of the consumption of antioxidant rich fruits and vegetables. Generally, dietary antioxidants are minerals, vitamins, fibers, and phytochemicals supplied by fruits and vegetables. Recently, much attention has been focused on new approaches of antioxidant therapy by providing antioxidant enzymes.

Thus, we will review the utilisation of animal models of oxidative stress and the preventive effects of some phytochemicals, micronutrients and enzymes against pathologies such as early atherosclerosis and obesity.

\section{Animal models of oxidative stress and pathologies}

\subsection{Atherosclerosis}

With the exception of a research by Adams et al. (2006) with a transgenic mice model, few studies have investigated the effect of plant material on atherosclerosis and oxidative stress in rodents (Nicolle et al., 2003; Nicolle et al., 2004); moreover, these studies were only focused on the effect of vegetables. Golden Syrian hamsters fed a fat rich diet develop dyslipidemia and atherosclerotic plaques, similar in many respects to human atheroma

\begin{tabular}{lc}
\hline Diet ingredient & Experimental diet \\
\hline Casein & 200 \\
DL-methionine & 3 \\
Corne starch & 393 \\
Sucrose & 154 \\
Cellulose & 50 \\
Mineral mix ${ }^{1}$ & 35 \\
Vitamin mix ${ }^{2}$ & 10 \\
Lard & 150 \\
Cholesterol & 5 \\
\hline
\end{tabular}

${ }^{1}$ Mineral mixture contained (mg/kg diet): $\mathrm{CaHPO}_{4}, 17,200 ; \mathrm{KCl}, 4000 ; \mathrm{NaCl}, 4000 ; \mathrm{MgO}, 420 ; \mathrm{MgSO}_{4}$, 2,000; $\mathrm{Fe}_{2} \mathrm{O}_{3}, 120 ; \mathrm{FeSO}_{4} .7 \mathrm{H}_{2} \mathrm{O}, 200$; trace elements, $400\left(\mathrm{MnSO}_{4} . \mathrm{H}_{2} \mathrm{O}, 98 ; \mathrm{CuSO}_{4} .5 \mathrm{H}_{2} \mathrm{O}, 20 ; \mathrm{ZnSO}_{4} .7 \mathrm{H}_{2} \mathrm{O}\right.$, 80; $\mathrm{CoSO}_{4} .7 \mathrm{H}_{2} \mathrm{O}, 0.16$; KI, 0.32; sufficient starch to bring to $40 \mathrm{~g}$ (per kg diet). ${ }^{2}$ Vitamin mixture containing (mg/kg diet): retinol, 12; cholecalciferol, 0.125; thiamin, 40; riboflavin, 30; pantothenic acid, 140; pyridoxine, 20; inositol, 300; cyanocobalamin, 0.1; menadione, 80; nicotinic acid, 200; choline, 2720; folic acid, 10; p-aminobenzoic acid, 100; biotin, 0.6; sufficient starch to bring to $20 \mathrm{~g}$ (per kg diet).

Table 1. Composition of the atherogenic diet $(\mathrm{g} / \mathrm{kg})$. 
(Vinson et al., 2011; Auger et al., 2002; Auger et al., 2005 a \& b). Hamsters were selected for these studies because of their responsiveness to plasma cholesterol lowering and antiatherogenic interventions (Kowala et al., 1991). Moreover, hamster has a plasma lipoprotein distribution similar to that of humans and LDL as the major plasma cholesterol carrier. To induce an oxidative stress, their high cholesterol and high fat diet was rendered deficient in vitamin $\mathrm{C}$ and $\mathrm{E}$ and in selenium (Table 1 ).

Thus, the arterial wall response to such a stress (fatty streak formation and aortic atherosclerosis emergence) was triggered and then the modulation of this effect by plant extracts or fruits and vegetables. In addition, for the first time in this model, we measured the modulation of oxidative stress parameters including cardiac production of superoxide anions and $\mathrm{NAD}(\mathrm{P}) \mathrm{H}$ oxidase expression.

\subsection{Obesity}

The high risk of oxidative stress in the obese is due to both overproduction of reactive oxygen species and low antioxidant defenses. In humans, obesity leads to increased lipid peroxidation and low activity of antioxidant enzymes such as superoxide dismutase $(\mathrm{Cu}-\mathrm{Zn}$ SOD) and glutathione peroxidase (GSHPx) in plasma and erythrocytes (Olusi, 2002). These oxidative stress markers are inversely correlated with insulin sensitivity. But insulin resistance (IR) appears as a key factor for oxidative risk. Hyperinsulinemia, correlated with the fat overload, contributes to a metabolic disorder of sulfur amino acids, leading to elevated homocysteine levels (Gallistl et al., 2000; Sanchez-Margalet et al., 2002) which increases the risk of cardiovascular disease. Moreover, in children (Morinobu et al., 2002), adolescents (Neuhouser et al., 2001) and adults obese (Wallstrom et al., 2001), it has been reported low plasma levels of $\alpha$-tocopherol, vitamin $C$ and carotenoids that are major micronutrients for the secondary antioxidant defense.

Obesity follows from numerous behavioral interactions, physiological and biochemical. It is associated with a reduced life expectancy and is an independent risk factor for CVD, the main cause of death worldwide. In addition, obese patients, particularly those with abdominal obesity due to accumulation of visceral fat, have a higher risk of impaired glucose tolerance and impaired fasting glucose, which often evolve into insulin resistance (IR) and type 2 diabetes mellitus (T2DM). Obesity and IR are frequently associated with hypertension, hyperhomocysteinemia and dyslipidemia (pro-atherogenic factors), nonalcoholic fatty liver disease (NAFLD) and nonalcoholic steatohepatitis (NASH), chronic inflammation and a prothrombotic state. These metabolic disorders and obesity, are grouped under the term metabolic syndrome. They are influenced by genetic and environmental factors (nutritional and/or hormonal) that can be easily studied in animal and cellular models.

The increasing morbidity from cardiovascular diseases and type 2 diabetes in the obese population suggests that obesity is associated with increased oxidative stress. Obesity can contribute to increased susceptibility to ROS. In the general population, several risk groups to high oxidative stress are identified (the elderly, smokers, those with an unbalanced diet), particularly obese patients in conjunction with reduced antioxidant defenses and/or strong radical production. 
Some dietary patterns and specific dietary components have been associated with reduced prevalence of CVD in humans. For example, the Mediterranean diet, characterized by a high fiber, low glycemic index carbohydrates, unsaturated fat, vitamins and antioxidant polyphenols, has been associated with a decreased incidence of CVD, obesity and T2DM. Patients with metabolic syndrome having a Mediterranean diet, exhibited a significant reduction in body weight and IR and it seems reasonable to attribute beneficial effects to antioxidants.

Thus, we have developed an animal model of diet-induced obesity (hamster) with metabolic syndrome (and therefore with oxidative stress) receiving a high-fat diet (Table 2), and then we measured metabolic characters (adipokines plasma levels) and we investigated the action mechanisms of dietary antioxidants at target organs such as liver (hepatic steatosis characterization and activity of $\mathrm{NAD}(\mathrm{P}) \mathrm{H}$ oxidase) or the heart (expression and activity of $\mathrm{NAD}(\mathrm{P}) \mathrm{H}$ oxidase, mitochondrial dysfunction). The activity of antioxidant enzymes (SOD, glutathione peroxidase, catalase) was also assessed and blood glucose and insulin, insulin resistance (HOMA-IR) and paraoxonase activity have been measured to assess the effects and action mechanisms on the metabolic syndrome itself.

\begin{tabular}{lc}
\hline Diet ingredient & Experimental diet \\
\hline$\%$ energy as protein & 18.89 \\
$\%$ energy as carbohydrate & 36.75 \\
$\%$ energy as fat & 44.36 \\
Fibre $(\mathrm{g} / 100 \mathrm{~g})$ & 5.90 \\
Lard $(\mathrm{g} / 100 \mathrm{~g})$ & 21.00 \\
Soyabean oil $(\mathrm{g} / 100 \mathrm{~g})$ & 3.00 \\
Cholesterol $(\mathrm{g} / 100 \mathrm{~g})$ & 0.10 \\
$\%$ saturated fat & 9.56 \\
$\%$ monounsaturated fat & 10.61 \\
$\%$ polyunsaturated fat & 3.86 \\
Energy density $(\mathrm{kj} / \mathrm{g})$ & 20.85 \\
\hline
\end{tabular}

Table 2. Composition of the obesogenic diet.

\section{Preventive effects of dietary antioxidants against atherosclerosis}

\subsection{Fruit and vegetable extract}

We studied the effects of a fruit and vegetable extract (Oxxynea ${ }^{\circledR}$ ) on such an animal model of atherosclerosis (Sutra et al., 2007). According to the manufacturer (Fytexia, Béziers, France), the powdered Oxxynea ${ }^{\circledR}$ extract was obtained from 22 varieties of antioxidant-rich fruits and vegetables including apple, asparagus, bilberry, apricot, black currant, broccoli, carrot, cherry, cucumber, garlic, grapefruit, green cabbage, olive, onion, orange, papaya, pineapple, red and white grapes, strawberry, tea, tomato, and wheat germ. Oxxynea ${ }^{\circledR}$ contains high level of catechins, that is, sum of procyanidin dimers B1, B2, B3, and B4 (1.14 $\mathrm{g} / 100 \mathrm{~g}$ ) and monomeric catechins (catechin, $0.55 \mathrm{~g} / 100 \mathrm{~g}$; epicatechin, $3.08 \mathrm{~g} / 100 \mathrm{~g}$; epichatechin-3-O-gallate, $4.10 \mathrm{~g} / 100 \mathrm{~g}$; epigallocatechin, $4.17 \mathrm{~g} / 100 \mathrm{~g}$; epigallocatechin-3-Ogallate, $21.33 \mathrm{~g} / 100 \mathrm{~g}$ ). Other phenolic compounds such as gallic acid and anthocyanins were detected in lower amounts $(0.15$ and $0.6 \mathrm{~g} / 100 \mathrm{~g}$, respectively). The extract also contained low levels of lycopene $(28 \mathrm{mg} / 100 \mathrm{~g})$ and vitamin C (4.92 mg/100 g). 
Thirty six hamsters were divided into two groups of 18 and fed an atherogenic diet for 12 weeks. They received by gavage either water or Oxxynea ${ }^{\circledR}$ in water at a human dose equivalent of 10 fruits and vegetables per day. Oxxynea lowered plasma cholesterol and non-HDL cholesterol, but not HDL-cholesterol, and increased plasma antioxidant capacity (Table 3).

\begin{tabular}{ccc}
\hline & Atherogenic diet & $\begin{array}{c}\text { Atherogenic diet } \\
\text { plus Oxxynea }\end{array}$ \\
\hline TC $^{2}, \mathrm{mmol}^{\circledR} \mathrm{L}$ & $9.54 \pm 0.20^{\mathrm{a}}$ & $8.42 \pm 0.16^{\mathrm{b}}$ \\
$\mathrm{HDLC}^{3}, \mathrm{mmol} / \mathrm{L}$ & $6.01 \pm 0.27^{\mathrm{a}}$ & $5.90 \pm 0.16^{\mathrm{a}}$ \\
Non-HDLC, $\mathrm{mmol} / \mathrm{L}$ & $3.12 \pm 0.15^{\mathrm{a}}$ & $2.68 \pm 0.17 \mathrm{~b}$ \\
Atherogenic index & $1.56 \pm 0.04^{\mathrm{a}}$ & $1.43 \pm 0.03^{\mathrm{b}}$ \\
PAC, $\mathrm{mmol} / \mathrm{L}$ & $1.29 \pm 0.06^{\mathrm{a}}$ & $1.42 \pm 0.10^{\mathrm{b}}$ \\
\hline
\end{tabular}

${ }^{1}$ Values are means \pm SEM, $n=18$. Data were analyzed by one-way ANOVA followed by the least significant difference test. For each dietary treatment, means in a column with different letters differ, $\mathrm{P}$ $<0.05 .{ }^{2} \mathrm{TC}$ : total cholesterol. ${ }^{3}$ HDLC : high-density lipoprotein cholesterol. ${ }^{4}$ Total cholesterol/HDLcholesterol.

Table 3. Effects of ingestion of a fruit and vegetable extract (Oxxynea ${ }^{\circledR}$ ) on plasma lipid concentrations and on plasma antioxidant capacity (PAC) in hamsters fed an atherogenic diet ${ }^{1}$.

As previously reported, a high fat diet led to an early increase in total and non-HDL cholesterol after 15 days of diet leading to lipid deposition on aortic arch at 84 days. Interestingly, the atherogenic diet-induced hypercholesterolemia is in parallel accompanied by a tendency of superoxide anion overproduction, which reaches the significance at 45 days (Figure 1 and Figure 2).

Oxxynea ${ }^{\circledR}$ reduced cardiac production of superoxide anion by $45 \%$, and p22phox subunit of NAD $(\mathrm{P}) \mathrm{H}$ oxidase expression by $59 \%$ (Figure 2).

Oxxynea ${ }^{\circledR}$ also strongly reduced the area of aortic fatty streak deposition by $77 \%$ (Figure 3). In agreement with oxidative hypothesis of atherosclerosis, it could be postulated that $\mathrm{NAD}(\mathrm{P}) \mathrm{H}$ oxidase expression and activity conspire with high non-HDL cholesterol level to induce foam cells and fatty streak.

The resulting improvement of atherogenic index (Table 3) obtained with fruit and vegetable extract extends the previous observation on the beneficial effects in lipid parameters obtained with grape polyphenols (Vinson et al., 2001).

Our findings suggest for the first time that the fruit and vegetable antioxidant extract could prevent both $\mathrm{NAD}(\mathrm{P}) \mathrm{H}$ oxidase expression and $\mathrm{O}_{2}{ }^{\circ}$ - overproduction in the heart from hypercholesterolemic hamster. Here again, $\mathrm{NAD}(\mathrm{P}) \mathrm{H}$ oxidase inhibition could be involved in prevention of LDL oxidation and further atherosclerosis steps. Beyond the vicious circles linked to LDL oxidation, the inhibition of reactive oxigen species (ROS) production by $\mathrm{NAD}(\mathrm{P}) \mathrm{H}$ oxidase system could also prevent other early events in cardiovascular diseases such as endothelial dysfunction or arterial remodelling. A recent study has shown that endothelium-dependent vasorelaxation is impaired in the high lipidfed golden syrian hamster (Georgescu et al., 2006). Our current results showing that the fruit and vegetable extract inhibits the overproduction of $\mathrm{O}_{2}{ }^{\circ}$ by $\mathrm{NAD}(\mathrm{P}) \mathrm{H}$ system strongly suggest that Oxxynea may prevent the endothelial dysfunction. Indeed, an overproduction of superoxide 

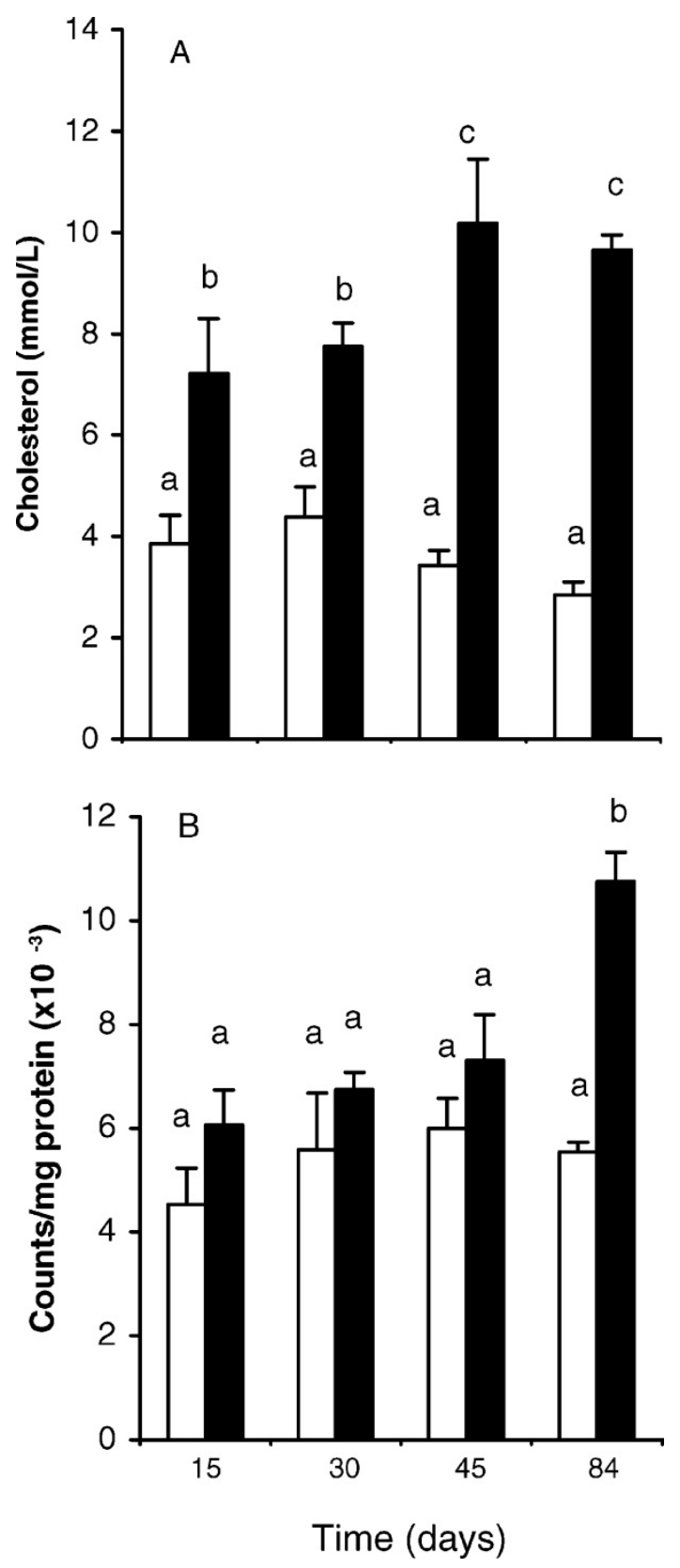

Fig. 1. Time course experiment of plasma cholesterol concentration (A) and superoxide anion production (B) in hamsters fed a standard diet (white bars) and in hamsters fed an atherogenic diet (black bars). Values are expressed as mean \pm SEM of triplicate wells $(n=6)$. For each dietary treatment, bars with different index letters differ $(\mathrm{P}<0.05)$. 


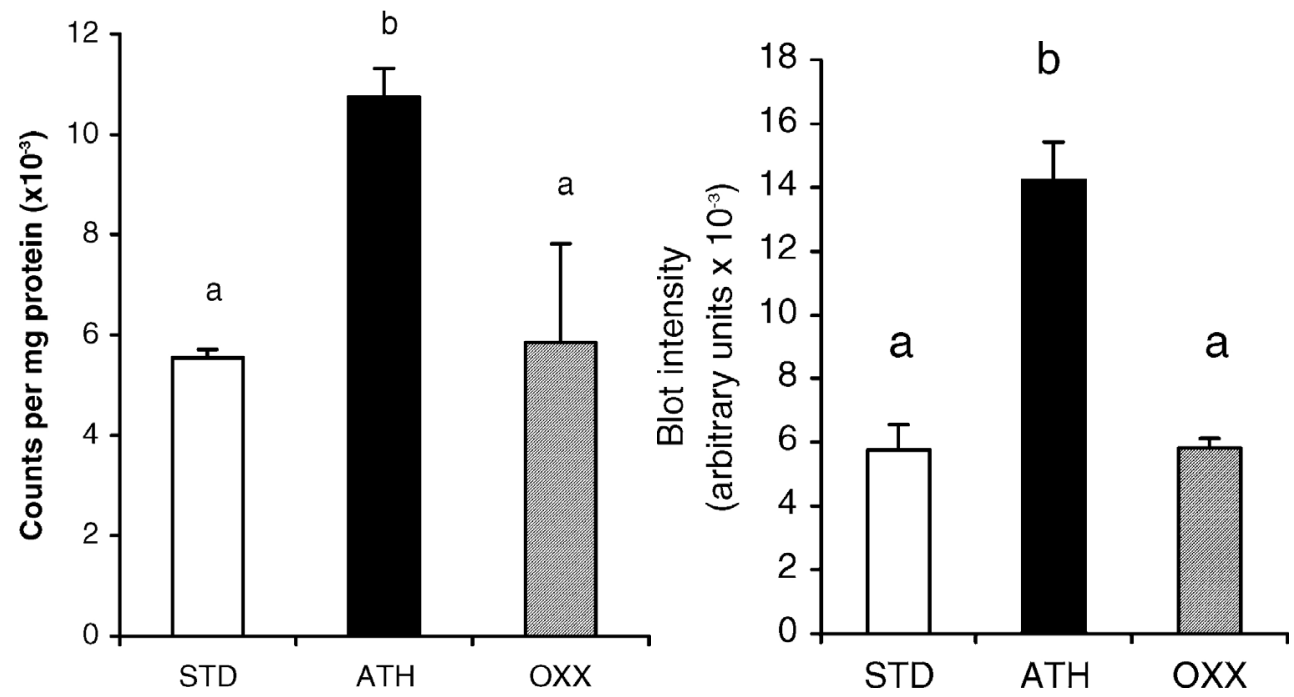

Fig. 2. Cardiac superoxide anion production (letf graph) and expression of the cardiac p22phox subunit of NAD $(\mathrm{P}) \mathrm{H}$ oxidase (right graph) in hamsters fed a standard or an atherogenic diet with (OXX) or without (ATH) Oxxynea during 84 days. Values are expressed as mean \pm SEM of triplicate wells $(n=6)$. For each dietary treatment, bars with different index letters differ $(\mathrm{P}<0.05)$.

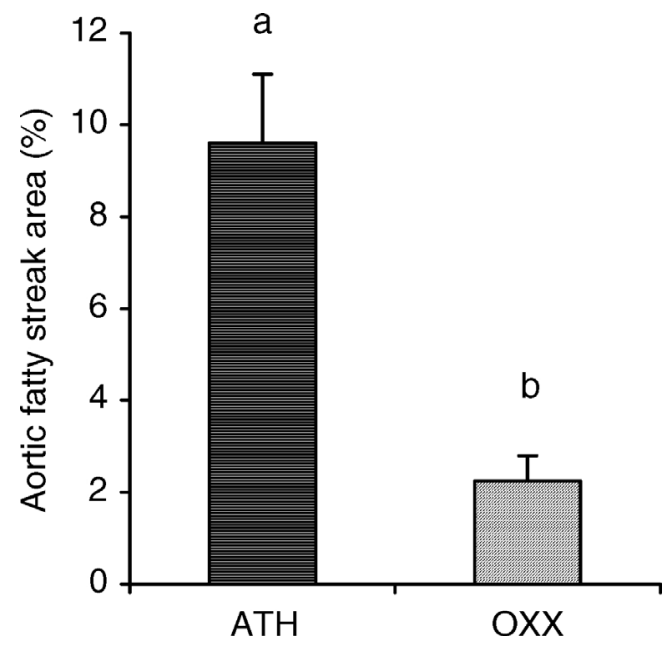

Fig. 3. Effects of ingestion of water $(\mathrm{ATH})$ or a fruit and vegetable extract Oxxynea ${ }^{\circledR}(\mathrm{OXX})$, on aortic fatty streak area in hamsters fed an atherogenic diet for 84 days. Values are expressed as mean \pm SEM $(n=12)$. Bars with different index letters differ $(P<0.05)$.

anion that could react with $\mathrm{NO}^{\circ}$ to produce peroxinitrite has been involved in the hypercholesterolemiainduced impairment of vasorelaxant system (Wagner et al., 2000). On the other hand, we have shown that an overproduction of ROS is strongly associated with 
cardiac remodelling, suggesting a pathogenic role of oxidative stress in its constitution (AlAwwadi et al., 2005). Pharmacoogical or nutritional intervention could prevent both $\mathrm{NAD}(\mathrm{P}) \mathrm{H}$ oxidase expression and activity and cardiac hypertrophy (Al-Awwadi et al., 2005). Our results showing that hypercholesterolemic diet activates and that vegetable and fruit extracts inhibit $\mathrm{NAD}(\mathrm{P}) \mathrm{H}$ expression and activity in the heart reinforce the hypothesis of a nutritional modulation of ROS enzymatic producing systems.

All of these results suggest that this extract acted by mechanisms operating both inside and outside a hypolipemic effect, especially an antioxidant effect. Although the constituent(s) responsible for these effetcs remain(s) unclear, candidates such as vitamin C, vitamin $E$, carotenoids, selenium, and polyphenols could act synergistically or additively to prevent atherosclerosis in the hamster model.

These findings support the view that chronic consumption of antioxidants supplied by fruits and vegetables has potential beneficial effects with respect to the development of atherosclerosis. The underlying mechanism is related mainly to inhibiting pro-oxidant factors and improving the serum lipid profile.

\subsection{Raspberry juices}

In another recent set of studies, the effects of raspberries on early atherosclerosis in Syrian hamsters were investigated using three juices prepared from var. Cardinal, Glen Ample and Tulameen berries (Suh et al., 2011). The hamsters received an atherogenic diet for 12 weeks and at the same time a juice at a daily dose corresponding to the consumption of $275 \mathrm{ml}$ by a $70 \mathrm{~kg}$ human. A control group (CTR) received the same diet with water instead juice. The principal polyphenolic compounds in the juices were anthocyanins and ellagitannins, which were present at concentrations of $218-305 \mathrm{mg} \cdot \mathrm{mL}^{-1}$ and $45-72 \mathrm{mg} \cdot \mathrm{mL}^{-1}$, respectively. The three juices had similar but not identical effects.
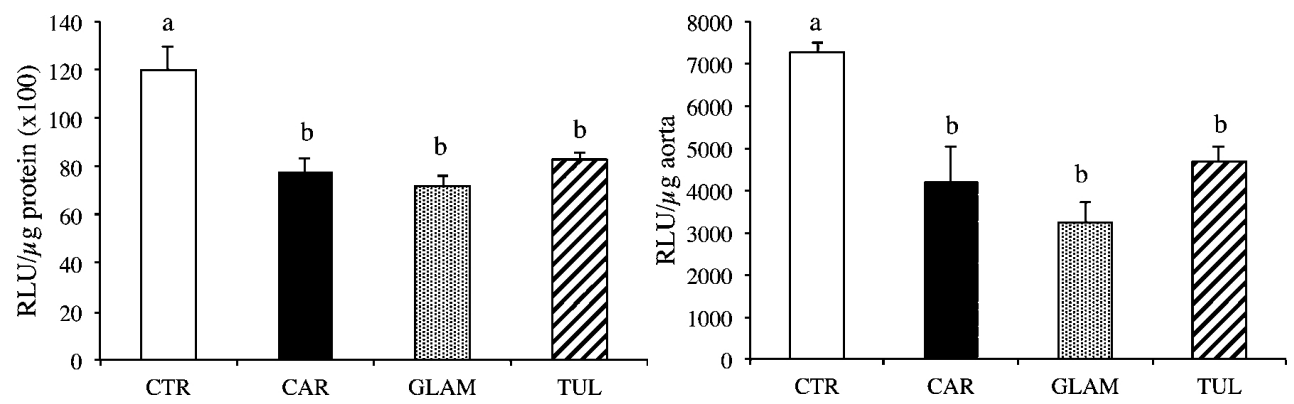

Fig. 4. Cardiac (left) and thoracic aorta (right) superoxide anion production (as Relative Luminescence Units) in hamsters fed a high-fat diet (CTR), or a CTR diet plus either Cardinal (CAR), Glen Ample (GLAM) or Tulameen raspberry juice (TUL) for 12 weeks. Values are expressed as mean $\pm \operatorname{SEM}(n=6)$.

They all inhibited cardiac and aortic production of superoxide anion (Figure 4) and increased hepatic glutathione peroxidase activity although only Tulameen juice brought about a significant increase in superoxide dismutase activity (Table 4). Glen Ample was the only juice to significantly increase plasma paraoxonase activity (Figure 5). 


\begin{tabular}{cccc}
\hline Diet & GSHPx & SOD & PON \\
& $U / m g$ protein & $U / m g$ protein & $U / m L$ \\
\hline Control & $945 \pm 45$ & $158 \pm 13$ & $60 \pm 16$ \\
Cardinal & $1412 \pm 76^{*}$ & $161 \pm 9$ & $70 \pm 17$ \\
Glen Ample & $1352 \pm 72^{*}$ & $144 \pm 10$ & $120 \pm 29^{*}$ \\
Tulameen & $1278 \pm 68^{*}$ & $203 \pm 12^{*}$ & $61 \pm 13$ \\
\hline
\end{tabular}

${ }^{1}$ Data expressed as mean values $\pm \operatorname{SEM}(n=12)$. For each dietary treatment, mean values in a column designated * are significantly different from the controls, P < 0.05. GSHPx: glutathione peroxidase. SOD: superoxide dismutase. PON: paraoxonase

Table 4. Hepatic antioxidant enzymes activities and plasma paraoxonase activity in hamsters fed an atherogenic diet plus a daily gavage of either water (control) or Cardinal, Glen Ample or Tulameen raspberry juice for 12 weeks ${ }^{1}$.

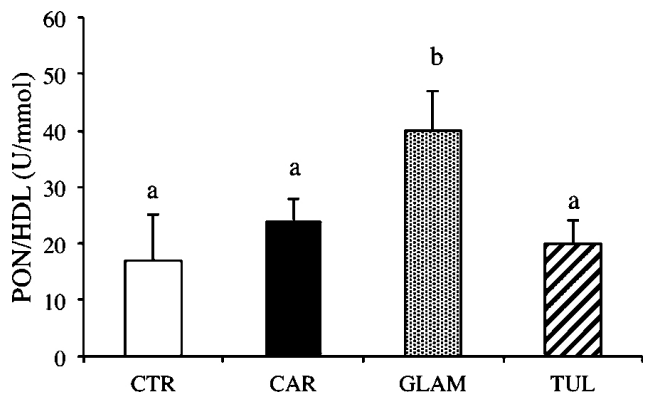

Fig. 5. Ratio paraoxonase activity (PON)/HDL concentration in hamsters fed a high-fat diet (CTR), or a CTR diet plus either Cardinal (CAR), Glen Ample (GLAM) or Tulameen raspberry juice (TUL) for 12 weeks. Values are mean \pm SEM $(n=6)$. For each dietary treatment, bars with different index letters are statistically significantly different $(\mathrm{P}<0.05)$.

All the juices lowered plasma triglyceride level while consumption of Tulameen and Cardinal, but not Glen Ample, significantly lowered plasma total cholesterol and LDLcholesterol (not shown here). Cardinal was the sole juice to significantly increase HDLcholesterol and likewise it also significantly reduced body weight. These findings suggest that moderate consumption of raspberry juices can help to prevent the development of early atherosclerosis, with the underlying mechanisms related to improved antioxidant status and serum lipid profiles.

\subsection{Apples, purple grape, apple juice and purple grape juice}

We also looked at how being fed various kinds of fruit affected the hamsters' risk of atherosclerosis (Décordé et al., 2008). 40 male Syrian golden hamsters were randomly divided into five groups. The animals were fed a diet to promote the development of artery hardening, and supplemented with mashed apple or purple grape, or the same volume of apple juice or purple grape juice, or water (control group) for 12 weeks. The amount of fruit the hamsters consumed was equivalent to three apples or three bunches of grapes daily for a human. Hamsters given juice drank the equivalent of four glasses daily for a person weighing 70 kilograms. 
The apples and grapes had about the same phenol content, while the purple grape juice had 2.5 times more phenols than apple juice. At the end of the study, total cholesterol levels were significantly reduced in the animals fed the fruit-supplemented diets, by $11 \%$ in apple group and $24 \%$ in the apple juice group, and $30 \%$ in the purple grape and 34 per cent in the purple grape juice group. This was attributed to the reductions in levels of non-HDL cholesterol. Compared with animals given water, those given fruit or fruit juice had less oxidative stress. The juices also outperformed the fruit for protecting against atherosclerosis, measured by the aortic fatty streak lesion area (AFSA). This value was reduced by $93 \%$ and $78 \%$ for the purple grape juice and the fruit, respectively, and by $60 \%$ and $48 \%$ for apple juice and apple, respectively (Figure 6).

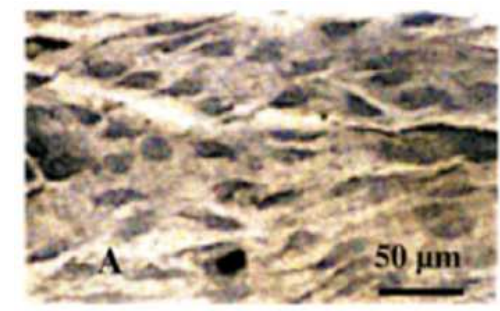

STANDARD

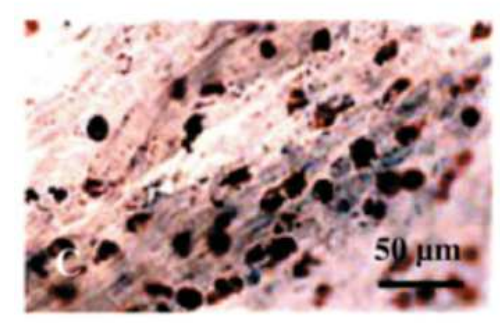

APPLE

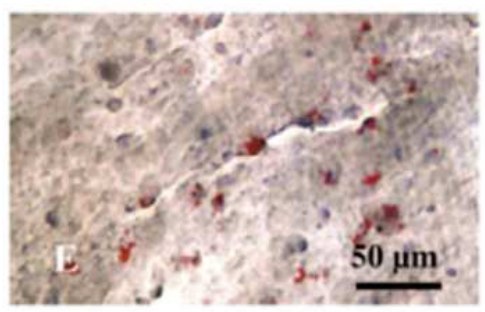

PURPLE GRAPE

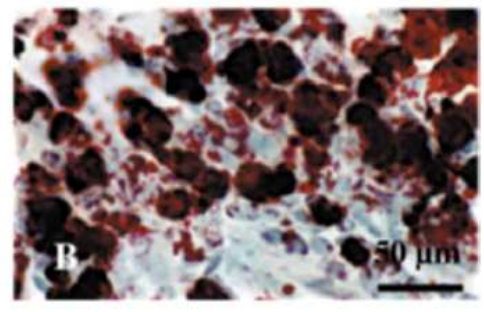

CONTROL

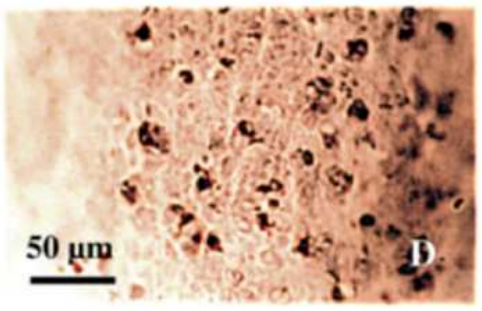

APPLE JUICE

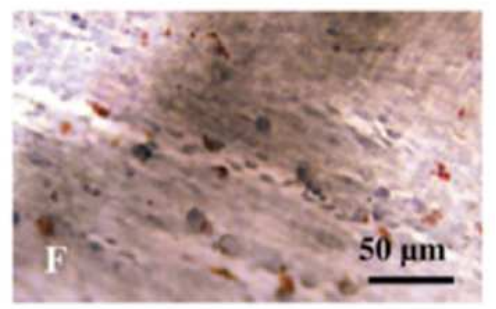

PURPLE GRAPE JUICE

Fig. 6. Photomicrographs of typical atherosclerotic lesions of the hamsters' aortic arch (photographed at $\times 40$ ) after a 12-wk experimentation period. Aortic fat deposits are stained in Oil Red O. (A) From non-atherogenic diet-fed hamsters (standard group). (B) From atherogenic diet-fed hamsters (control group). (C, D, E, F) From atherogenic diet-fed hamsters receiving either apples $(C)$, apple juice $(D)$, purple grape $(E)$, or purple grape juice by gavage. 
The results show for the first time that long-term consumption of antioxidants supplied by apple and purple grape, especially phenolic compounds, prevents the development of atherosclerosis in hamsters, and that processing can have a major impact on the potential health benefits of a product. Flavonoids, especially anthocyanins and catechins in purple grape and purple grape juice, generally have more hydroxyl groups than phenolic acids found in apple and apple juice. This could explain why purple grape juice and purple grape displayed a better efficacy than apple and apple juice against early atherosclerosis. Nevertheless, these beneficial effects cannot only be attributed to their phenolic contents, but to the result of the action of different antioxidant compounds present in the fruits (vitamin C, carotenoids, polyphenols) and to possible synergistic and antagonist effects still unknown. It provides encouragement that fruit and fruit juices may have a significant clinical and public health relevance.

\subsection{Red berry juices and teas}

Also, consuming antioxidant-rich raspberry juice or tea may prevent artery hardening, and lead to improvements in heart health (Rouanet et al., 2010). Measures of atherosclerosis were reduced in hamsters with high cholesterol levels following consumption of raspberry, strawberry and bilberry juices and green and black tea, with the benefits were significantly greater for raspberry and green tea. Consuming the equivalent of $275 \mathrm{~mL}$ by a $70 \mathrm{~kg}$ human led to reductions in fat deposits in the aorta of up to 96 per cent after 12 weeks (Figure 7).

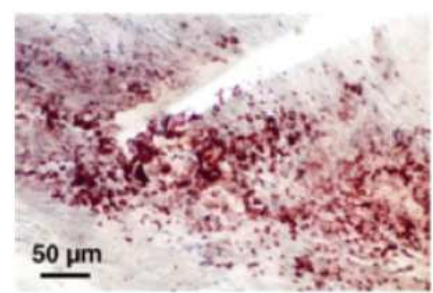

Control

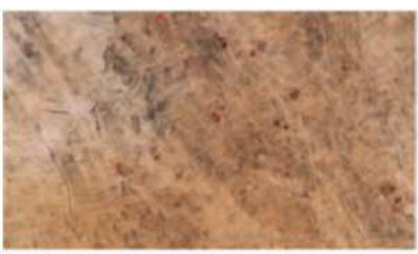

Raspberry

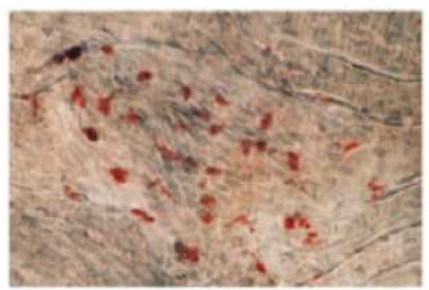

Bilberry

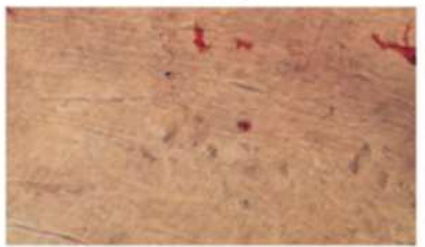

Green tea

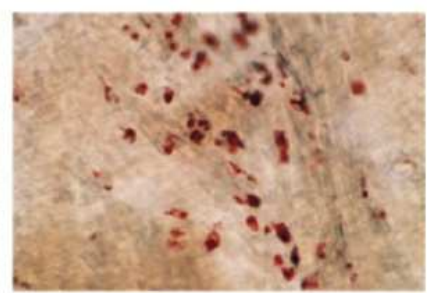

Strawberry

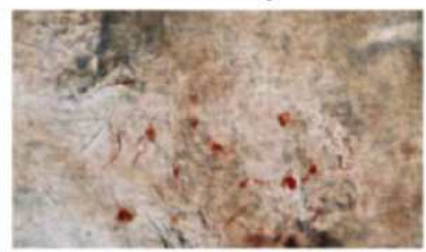

Black tea

Fig. 7. Photomicrographs of hamster aortic arches after 12 weeks on an atherogenic diet (control) and 12 weeks on an atherogenic diet supplemented with either strawberry juice, bilberry juice, raspberry juice, green tea or black tea. The micrographs are examples of the aortic arch surface covered by lipid inclusion in the intima with lipids coloured red using Oil Red O stain. All micrographs have the same scale. 
These findings suggest that moderate consumption of berry juices and teas can help prevent the development of early atherosclerosis. Atherosclerosis, or hardening of the arteries, is a major risk factor for cardiovascular disease, which causes almost 50 per cent of deaths in Europe, and is reported to cost the EU economy about $€ 169 \mathrm{bn}$ ( $\$ 202 \mathrm{bn})$ per year. While all of the beverages exerted beneficial effects, the composition and concentration of individual phenolic compounds varied substantially between the five beverages. This indicates that anti-atherosclerotic effects can be induced by a diversity of phenolic compounds rather than a few specific components.

\subsection{Phenolic-rich extracts from grape seed}

Elsewhere, we evaluated the antiatherosclerotic effect of commercially available phenolicrich extracts from grape seeds (ExGrape seeds, EGS; grape seed extract, GSE) and marc (ExGrape total, EGT) in cholesterol-fed hamsters and to investigate possible operating mechanisms (Auger et al., 2004). These extracts fed at a moderate dose mimicking two glasses of red wine per meal reduced plasma cholesterol $(-11 \%$ on average) but did not affect plasma antioxidant capacity of hamsters. The extracts prevented the development of aortic atherosclerosis by 68\% (EGS), 63\% (EGT), and 34\% (GSE) (Figure 8).

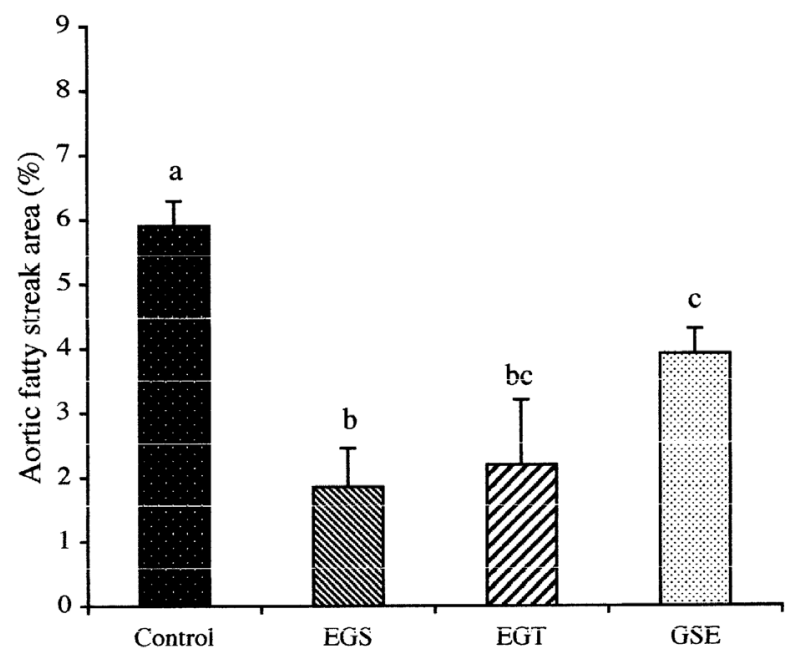

Fig. 8. Effects of force-feeding water (control), a procyanidin-rich white grape seed extract (EGS), a marc extract from red and white grapes, rich in anthocyanins (EGT), or a grape seed extract (GSE) on aortic fatty streak area (AFSA) in hamsters fed an atherogenic diet for 12 weeks. AFSA is expressed as a percentage of the total aortic area surveyed. Each bar represents mean \pm SEM from eight hamsters. Bars with different letters differ, $\mathrm{P}<0.05$.

Elsewhere, in an ex vivo experiment using rat aortic rings, EGS $(7 \mu \mathrm{g} / \mathrm{mL})$ induced $77 \%$ endothelium-dependent relaxation, whereas EGT and GSE $(30 \mu \mathrm{g} / \mathrm{mL})$ induced 84 and $72 \%$, respectively (Figure 9). 

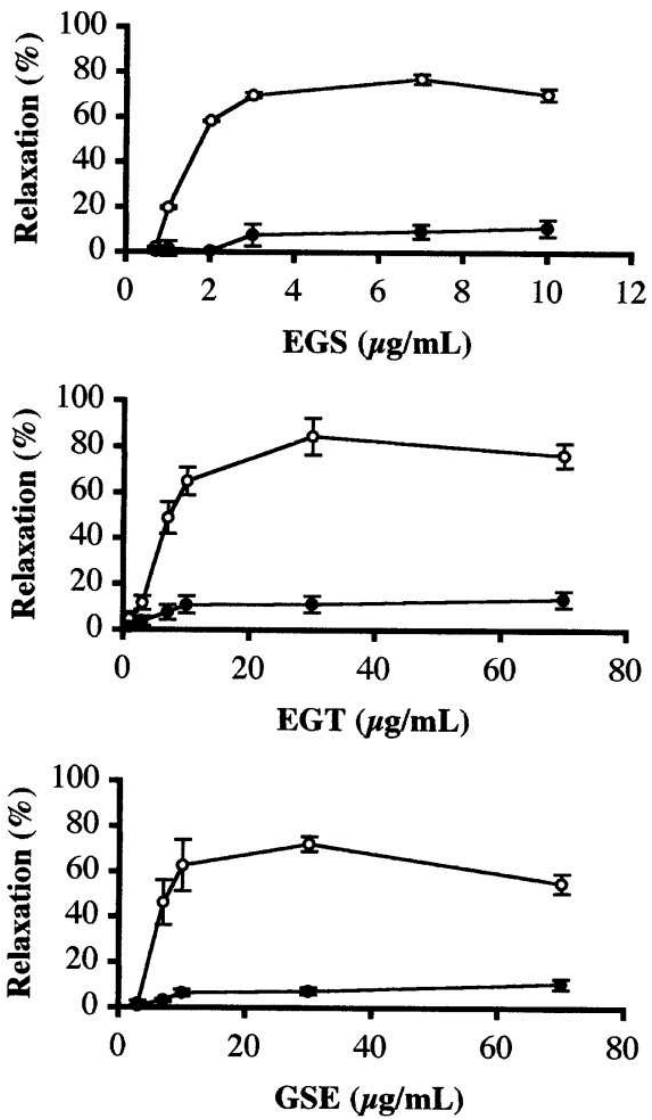

Fig. 9. Concentration-response curves for the relaxation of isolated aortic rings of rat by EGS, EGT, and GSE in the presence $(\mathrm{O})$ or in the absence $(\bullet)$ of endothelium. Each point represents mean \pm SEM from eight rats.

These results suggests that phenolic extracts from grape seeds and marc are beneficial to inhibit atherosclerosis by indirect mechanism(s).

\subsection{Wines}

We have thus studied the effects of a white wine enriched with polyphenols (PEWW) from Chardonnay grapes and of a sparkling red wine (SRW) from Pinot Noir and Chardonnay grapes for the first time on early atherosclerosis in hamsters (Auger et al., $2005 \mathrm{~b}$ ). Animals were fed an atherogenic diet for 12 weeks. They received by gavage PEWW, SRW, ethanol 12\% (ETH), or water as control (mimicking a moderate consumption of $\sim 2$ red wine glasses per meal for a $70 \mathrm{~kg}$ human). Plasma cholesterol concentrations were lower in groups that consumed PEWW and SRW accompanied by an increase in the ratio apo A-1/apo B (Table 5). 


\begin{tabular}{ccccc}
\hline & Control & Ethanol 12\% & PEWW & SRW \\
\hline TC $^{2}, m m o l / L$ & $10.39 \pm 0.65 \mathrm{a}$ & $9.65 \pm 0.54 \mathrm{ab}$ & $8.96 \pm 0.20^{\mathrm{b}}$ & $8.90 \pm 0.28 \mathrm{~b}$ \\
$\mathrm{HDL}^{\mathrm{a}} \mathrm{C}^{3}, \mathrm{mmol} / \mathrm{L}$ & $3.74 \pm 0.37$ & $3.71 \pm 0.15$ & $3.61 \pm 0.14$ & $3.50 \pm 0.17$ \\
$\mathrm{TG}^{4}, \mathrm{mmol} / \mathrm{L}$ & $1.37 \pm 0.17$ & $1.15 \pm 0.10$ & $1.19 \pm 0.12$ & $1.26 \pm 0.07$ \\
ApoA-1, $\mathrm{g} / \mathrm{L}$ & $1.70 \pm 0.21^{\mathrm{a}}$ & $2.20 \pm 0.12 \mathrm{~b}$ & $1.98 \pm 0.09 \mathrm{ab}$ & $1.94 \pm 0.15 \mathrm{ab}$ \\
ApoB, $\mathrm{g} / \mathrm{L}$ & $0.36 \pm 0.03$ & $0.29 \pm 0.02$ & $0.32 \pm 0.01$ & $0.30 \pm 0.02$ \\
ApoA-1/ApoB & $4.64 \pm 0.58 \mathrm{a}$ & $7.38 \pm 0.66^{\mathrm{b}}$ & $6.07 \pm 0.24 \mathrm{~b}$ & $6.44 \pm 0.77 \mathrm{~b}$ \\
\hline
\end{tabular}

${ }^{1}$ Values are means $\pm S E M, n=8$. Data were analyzed by one-way ANOVA followed by the least significant difference test. For each dietary treatment, means in a column with different letters differ, $\mathrm{P}<0.05$. ${ }^{2}$ Total cholesterol. ${ }^{3}$ High-density lipoprotein cholesterol. 4 Triglycerides.

Table 5. Effects of force-feeding water (Control), 12\% ethanol, polyphenols-enriched Chardonnay white wine (PEWW), or sparkling Pinot noir red wine (SRW) on plasma lipid and apolipoprotein concentrations of hamsters fed an atherogenic diet for 12 weeks ${ }^{1}$.

\begin{tabular}{ccccc}
\hline & Control & Ethanol 12\% & PEWW & SRW \\
\hline \multicolumn{4}{c}{ units. $\mathrm{mg}^{-1}$ of protein } \\
SOD & $7.28 \pm 1.15^{\mathrm{a}}$ & $6.74 \pm 0.97 \mathrm{a}$ & $10.07 \pm 1.51 \mathrm{~b}$ & $10.78 \pm 1.82 \mathrm{~b}$ \\
GSHPx $\left(\times 10^{-2}\right)$ & $11.47 \pm 1.93$ & $9.77 \pm 1.77$ & $10.93 \pm 2.37$ & $11.32 \pm 2.95$ \\
CAT & $108.27 \pm 4.94 \mathrm{a}$ & $100.32 \pm 6.62 \mathrm{a}$ & $125.20 \pm 8.49 \mathrm{~b}$ & $125.04 \pm 6.59 \mathrm{~b}$ \\
PAC, $\mathrm{mmol} / \mathrm{L}$ & $0.97 \pm 0.03 \mathrm{a}$ & $1.08 \pm 0.05^{\mathrm{b}}$ & $1.12 \pm 0.02 \mathrm{~b}$ & $0.93 \pm 0.10^{\mathrm{a}}$ \\
\hline
\end{tabular}

${ }^{1}$ Values are means $\pm S E M, n=8$. Data were analyzed by one-way ANOVA followed by the least significant difference test. For each dietary treatment, means in a column with different letters differ, $\mathrm{P}<0.05$.

Table 6. Effects of force-feeding water (Control), 12\% ethanol (ETH), polyphenols-enriched Chardonnay white wine (PEWW), or sparkling Pinot noir red wine (SRW) on liver superoxide dismutase (SOD), glutathione peroxidase (GSHPx), and catalase (CAT), and plasma antioxidant capacity (PAC) in hamsters fed an atherogenic diet for 12 weeks ${ }^{1}$.

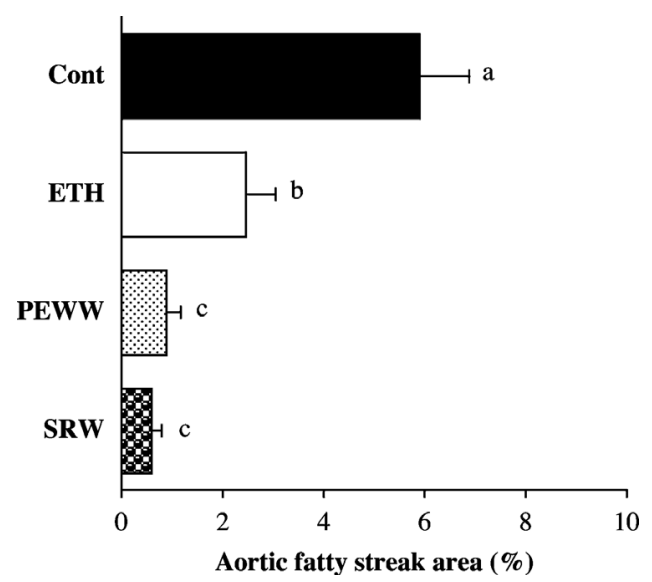

Fig. 10. Effects of daily force-feeding water (control), $12 \%$ ethanol (ETH), phenolics-enriched white wine (PEWW), or sparkling red wine (SRW) on aortic fatty streak area (AFSA) in hamsters fed an atherogenic diet for 12 weeks. Values are means $\pm \mathrm{SEM}, n=8$. Bars with different index letters differ, $\mathrm{P}<0.05$. 
Liver-specific activities of superoxide dismutase and catalase were significantly increased by PEWW (38 and 16\%, respectively) and by SRW (48 and 15\%, respectively). PEWW and ETH significantly increased plasma antioxidant capacity (Table 6). Aortic fatty streak area (AFSA) was significantly strongly reduced in the groups receiving PEWW $(85 \%)$ and SRW $(89 \%)$ in comparison with the control. AFSA was reduced by ethanol to a lesser extent (58\%) (Figure 10).

These data suggest that tannins from the phenolics-enriched white wine induce a protective effect against early atherosclerosis comparable to that produced by sparkling red wine containing tanins and anthocyanins and dissociated from the antioxidant action of these compounds.

\subsection{Pure phenolics}

To get more information about the effects and mechanisms of action of polyphenols, pure phenolic compounds catechin (Cat), quercetin (Qer), and resveratrol (Res) present in red wine on early atherosclerosis were studied in hamsters (Auger et al., 2005 a). Hamsters $(n=$ 32) were divided into 4 groups of 8 and fed an atherogenic diet for 12 weeks. They received by force-feeding $7.14 \mathrm{~mL} /\left(\mathrm{kg} \mathrm{BW} / \mathrm{d}^{-1}\right)$ Cat, Qer, or Res in water $\left[2.86 \mathrm{mg} /\left(\mathrm{kg} \mathrm{BW} / \mathrm{d}^{-1}\right)\right.$ for Cat and $0.143 \mathrm{mg} /\left(\mathrm{kg} \mathrm{BW} / \mathrm{d}^{-1}\right)$ for Qer and Res], mimicking a moderate consumption of alcohol-free red wine (equivalent to that supplied by the consumption of about two glasses of red wine per meal for a $70 \mathrm{~kg}$ human), or water as control. Plasma cholesterol concentration was lower in groups that consumed phenolics than in controls.

\begin{tabular}{ccllc}
\hline Exptl group & Controls & Catechin & Quercetin & Resveratrol \\
\hline TC $^{2}, \mathrm{mmol} / \mathrm{L}$ & $10.0 \pm 0.25^{\mathrm{a}}$ & $9.10 \pm 0.31^{\mathrm{b}}$ & $9.00 \pm 0.23^{\mathrm{b}}$ & $9.25 \pm 0.12^{\mathrm{b}}$ \\
HDLC $^{3}, \mathrm{mmol} / \mathrm{L}$ & $3.61 \pm 0.36$ & $3.62 \pm 0.15$ & $3.68 \pm 0.17$ & $3.83 \pm 0.24$ \\
TG $^{4}, \mathrm{mmol} / \mathrm{L}$ & $1.37 \pm 0.19 \mathrm{a}$ & $1.20 \pm 0.05^{\mathrm{a}}$ & $1.11 \pm 0.05^{\mathrm{b}}$ & $1.45 \pm 0.08^{\mathrm{a}}$ \\
Apo-A1, g/L $_{\text {Apo-B, g/L }}$ & $1.70 \pm 0.21^{\mathrm{a}}$ & $2.14 \pm 0.13^{\mathrm{b}}$ & $2.07 \pm 0.13^{\mathrm{ab}}$ & $2.02 \pm 0.09^{\mathrm{a}}$ \\
Apo-A1/Apo-B & $0.36 \pm 0.03$ & $0.33 \pm 0.02$ & $0.32 \pm 0.02$ & $0.35 \pm 0.03$ \\
\hline
\end{tabular}

${ }^{1}$ Values are means \pm SEM, $n=8$. Data were analyzed by one-way ANOVA followed by the least significant difference test. For each dietary treatment, meansin a column with different letters differ, $\mathrm{P}<$ 0.05. ${ }^{2}$ Total cholesterol. ${ }^{3}$ High-densitylipoprotein cholesterol. ${ }^{4}$ Triglycerides.

Table 7. Effects of daily force feeding of water (Control), Catechin, Quercetin, or Resveratrol in water on plasma lipid and apolipoprotein concentrations in hamsters fed an atherogenic diet for 12 weeks'1.

The increase in plasma apolipoprotein (Apo) A1 concentration was mainly due to Cat (26\%) and Qer $(22 \%)$ and to a lesser extent, but nonsignificantly, Res (19\%). Apo-B was not affected (Table 7).

Plasma antioxidant capacity was not improved, and there was no sparing effect on plasma vitamins A and E. Plasma iron and copper concentrations were not modified nor were liver superoxide dismutase and catalase activities. A sparing effect of Qer on liver glutathione peroxidase activity appeared, whereas Cat and Res exhibited a smaller effect. Aortic fatty streak area was significantly reduced in the groups receiving Cat $(84 \%)$ or Qer $(80 \%)$ or Res $(76 \%)$ in comparison with the controls (Figure 11). 


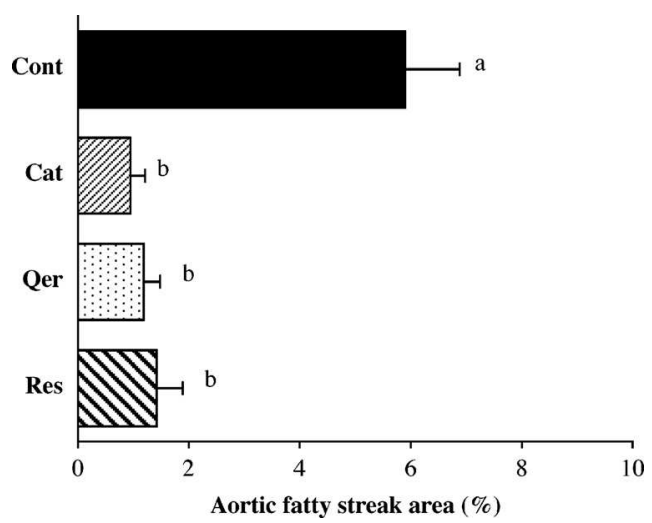

Fig. 11. Effects of daily force feeding of water (control, Cont), catechin (Cat), quercetin (Qer), or resveratrol (Res) on aortic fatty streak area (AFSA) in hamsters fed an atherogenic diet for 12 weeks. AFSA is expressed as a percentage of the total aortic area surveyed. Bars with different letters differ, $\mathrm{P}<0.05$.

These findings demonstrate that catechin, quercetin, and resveratrol at nutritional doses prevent the development of atherosclerosis through several indirect mechanisms.

\subsection{Selenium-rich microalgae}

Selenium (Se) has received considerable attention as an essential micronutrient for animals and humans. It functions in the active site of a large number of selenium-dependent enzymes such as glutathione peroxidase and is associated with anticancer and other physiological functions (Ip et al., 2000; Miller et al., 2001). The lack of Se in food may cause different diseases such as cardiovascular disease (Shamberger et al., 1978), cancer (Schrauzer et al., 1977; Salonen et al., 1984), rheumatoid arthritis (Tarp et al., 1985), cataract (Fecondo \& Augusteyn, 1983) and anemia (Chen et al., 1999). The major forms of selenium occurring in foodstuffs are the organic, protein-associated forms, selenomethionine (SeMet, plant and animal sources) and selenocysteine (SeCys, animal sources). Selenate is also present in some foodstuffs (Olson \& Palmer, 1978), and in selenium-deficient areas inorganic selenium salts (selenite, selenate) are added to the food (Van Vleet, 1980). Elsewhere, it is generally believed that organic Se compounds are better and safer than inorganic Se as dietary supplements ; therefore, in response to the need for Se to support human health, seleniumenriched foods have been developed and commercialized (Stoewsand et al., 1989). In the search for an economical source of organic nutritional forms of Se, we attempted to increase the normally low Se content of spirulina (Spirulina platensis) by growing it in Se-enriched medium (Cases et al., 2001; Cases et al., 2002) and suggested it represents a promising source for commercial large-scale production of organic Se, as compared with other plants (Cases et al., 2002). Spirulina is a blue-green microalga belonging to the cyanobacteria family, commercially available for human consumption and used as a functional food for humans because of its high concentration of protein and other nutritional elements. Phycocyanin (PC) and allophycocyanin are blue water-soluble photosynthetic pigments derived from cyanobacteria (blue-green algae) such as spirulina. They have been used as nutrients for 
both human and animal consumption, as natural dyes for food and cosmetics and as pharmaceuticals (Chen et al., 1996). In a recent work, we suggested that in Se-rich Spirulina, organic Se was mainly located in phycocyanin (Cases et al., 2002); more recently, this was corroborated by a work of Huang et al. (2001).

Previous reports have shown that a protean extract of Spirulina platensis is a potent freeradical scavenger (hydroxyl and peroxyl radicals) and inhibits microsomal lipid peroxidation; it has also been observed that an increase in phycocyanin content was related to an increase in the antioxidant activity in different fractions, and therefore phycobiliprotein phycocyanin is the component mainly responsible for the antioxidant activity (Pinero Estrada et al., 2001). Phycocyanin has also been described as a strong antioxidant (Bhat \& Madyastha, 2000; Bhat \& Madyastha, 2001) and anti-inflammatory (Reddy et al., 2000) natural compound. It is similar in chemical structure to bilirubin, and acts as a powerful scavenger of reactive oxygen species (ROS) in various in vitro and in vivo experimental models (Stocker et al., 1990).

It is now well recognized that an increased formation of oxygen radicals and other oxygen derivatives frequently accompanies tissue damage. Today, there is an explosive interest in the use of antioxidant nutritional supplements. Epidemiological evidence suggests that intake of some vitamins, minerals, and other food constituents may help to protect against heart disease, cancer and the ageing process, and that antioxidants may have a protective effect, either in preventing these diseases or lessening the severity of the diseases upon their onset. Many of their activities are mediated by ROS, which are generated during the oxidative burst (Aruoma, 1994; Imlay \& Linn, 1998). Hence, it is expected here that chronic diseases, particularly atherosclerosis, may be prevented by spirulina and phycocyanin and their Se-enriched forms.

Only two studies have suggested that Spirulina platensis concentrate imparts a hypocholesterolemic effect in rats (Iwata et al., 1990) and humans (Nakaya et al., 1998), and others more recently (Nagaok et al., 2005) provided the first direct evidence that phycocyanin is a novel hypocholesterolemic protein derived from Spirulina platensis that can powerfully influence rat serum cholesterol concentrations. Atherosclerosis may be characterized according to three theories (oxidative, inflammatory and hypercholesterolemic); since selenium takes part to the antioxidant defense and PC has been shown to possess antioxidant, anti-inflammatory and hypocholesterolemic properties, we hypothesized that PC and SePC might prevent this pathology.

Thus, the effects of spirulina and its chromophore phycocyanin, both without bound Se or selenium-enriched, were studied on plasma cholesterol, early atherosclerosis, cardiac production of superoxide anions, and $\mathrm{NAD}(\mathrm{P}) \mathrm{H}$ oxidase expression in hamsters fed a highcholesterol / low antioxidant diet (Riss et al., 2007). Forty hamsters were divided into 5 groups of 8 and fed an atherogenic diet for 12 weeks. They received by gavage either 7.14 $\mathrm{mL} /\left(\mathrm{kg} \mathrm{BW} / \mathrm{d}^{-1}\right)$ phycocyanin (PC), Se-rich phycocyanin (SePC), spirulina (SP) or Se-rich spirulina (SeSP) in water, or water as control. SeSP and SePC supplied $0.4 \mu \mathrm{g}$ of Se per $100 \mathrm{~g}$ body weight. Plasma cholesterol and non- HDL cholesterol concentrations were lower in group consuming SePC. HDL-cholesterol was never affected. SePC significantly increased plasma antioxidant capacity by $42 \%$ compared with controls (Table 8 ). 


\begin{tabular}{|c|c|c|c|c|c|}
\hline Group & Controls & PC & SePC & SP & SeSP \\
\hline $\mathrm{TC}^{2}, \mathrm{mmol} / \mathrm{L}$ & $7.54 \pm 0.31^{\mathrm{a}}$ & $7.02 \pm 0.16^{b}$ & $6.79 \pm 0.28^{b}$ & $7.22 \pm 0.28^{\mathrm{ab}}$ & $7.09 \pm 0.18^{\mathrm{ab}}$ \\
\hline $\mathrm{HDLC}^{3}, \mathrm{mmol} / \mathrm{L}$ & $4.51 \pm 0.44^{\mathrm{a}}$ & $4.25 \pm 0.33^{a}$ & $4.58 \pm 0.43^{a}$ & $4.59 \pm 0.28^{a}$ & $4.39 \pm 0.30^{a}$ \\
\hline $\begin{array}{l}\text { Non-HDLC, } \\
\mathrm{mmol} / \mathrm{L}\end{array}$ & $3.04 \pm 0.42^{a}$ & $2.78 \pm 0.29 \mathrm{ab}$ & $2.21 \pm .39 \mathrm{~b}$ & $2.53 \pm 0.21^{\mathrm{ab}}$ & $2.70 \pm 0.33 \mathrm{ab}$ \\
\hline $\begin{array}{l}\text { Atherogenic } \\
\text { index }\end{array}$ & $1.68 \pm 0.29 \mathrm{a}$ & $1.66 \pm 0.15^{\mathrm{ab}}$ & $1.48 \pm 0.11^{b}$ & $1.58 \pm 0.06^{\mathrm{ab}}$ & $1.61 \pm 0.11^{\mathrm{ab}}$ \\
\hline $\mathrm{PAC}, \mathrm{mmol} / \mathrm{L}$ & $0.88 \pm 0.06^{\mathrm{a}}$ & $1.18 \pm 0.09 \mathrm{bc}$ & $1.25 \pm 0.09 \mathrm{~b}$ & $0.99 \pm 0.08^{c}$ & $1.05 \pm 0.07 \mathrm{c}$ \\
\hline $\begin{array}{l}\mathrm{GSHPx}^{5}, \mathrm{U} / \mathrm{mg} \\
\text { protein }\end{array}$ & $41.07 \pm 1.23^{a}$ & $4.67 \pm 0.74^{b}$ & $5.72 \pm 1.27 \mathrm{~b}$ & $5.00 \pm 0.62^{b}$ & $5.59 \pm 1.41^{b}$ \\
\hline $\begin{array}{l}\mathrm{SOD}^{6}, \mathrm{U} / \mathrm{mg} \\
\text { protein }\end{array}$ & $6.72 \pm 0.52^{\mathrm{a}}$ & $3.17 \pm 0.38^{b}$ & $3.00 \pm 0.32^{b}$ & $2.29 \pm 0.26^{b}$ & $3.36 \pm 0.90^{b}$ \\
\hline
\end{tabular}

${ }^{1}$ Values are means \pm SEM, $n=8$. Data were analyzed by one-way ANOVA followed by the Least Significant Difference test. For each dietary treatment, means in a column with different superscripts differ, $P<0.05 .{ }^{2} \mathrm{TC}$ : total cholesterol. ${ }^{3}$ HDLC $:$ high density lipoprotein cholesterol. ${ }^{4}$ Total cholesterol/HDL-cholesterol. ${ }^{5}$ Glutathione peroxidase. ${ }^{6}$ Superoxide dismutase.

Table 8. Effects of ingestion phycocyanin (PC), Se-rich phycocyanin (SePC), spirulina (SP) and Se-rich spirulina (SeSP) on plasma lipid concentrations and antioxidant capacity (PAC), and on liver antioxidant enzymes activity (GSHPx and SOD) in hamsters fed an atherogenic diet ${ }^{1}$.

A sparing effect in liver glutathione peroxidase ( $87 \%$ on average) and superoxide dismutase (56\% on average) activity was observed for all the groups compared to controls. Aortic fatty streak area was significantly reduced in the experimental groups (Figure 12), especially by PC $(82 \%)$ and SePC (85\%).

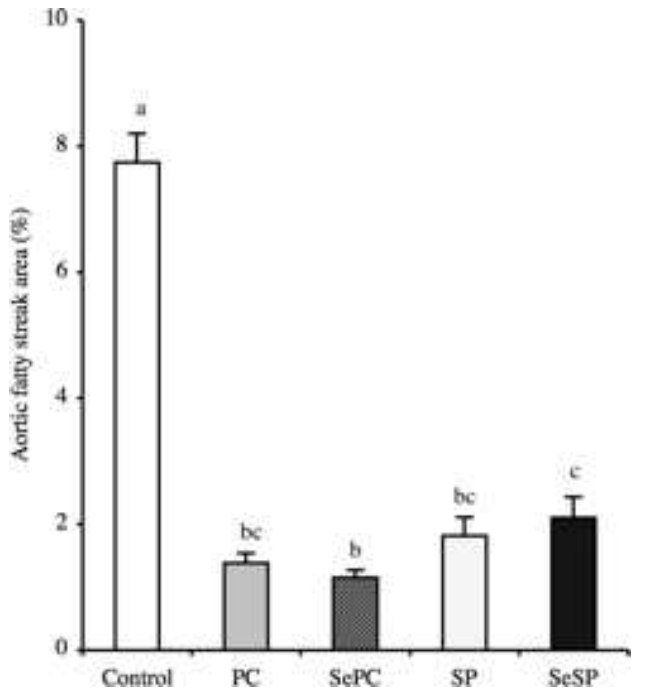

Fig. 12. Effects of daily force-feeding water (control) or phycocyanin (PC), Se-rich phycocyanin (SePC), spirulina (SP) or Se-rich spirulina (SeSP), on aortic fatty streak area in hamsters fed an atherogenic diet for 12 weeks. Values are means \pm SEM, $(n=8)$. Bars with different index letters differ, $\mathrm{P}<0.05$. 
Cardiac production of superoxide anion significantly decreased by $\sim 46-76 \%$ in the four experimental groups and especially in SePC group (76\%). The expression of p22phox subunit of $\mathrm{NAD}(\mathrm{P}) \mathrm{H}$ oxidase decreased by $34 \%$ after consumption of SePC (Figure 13).
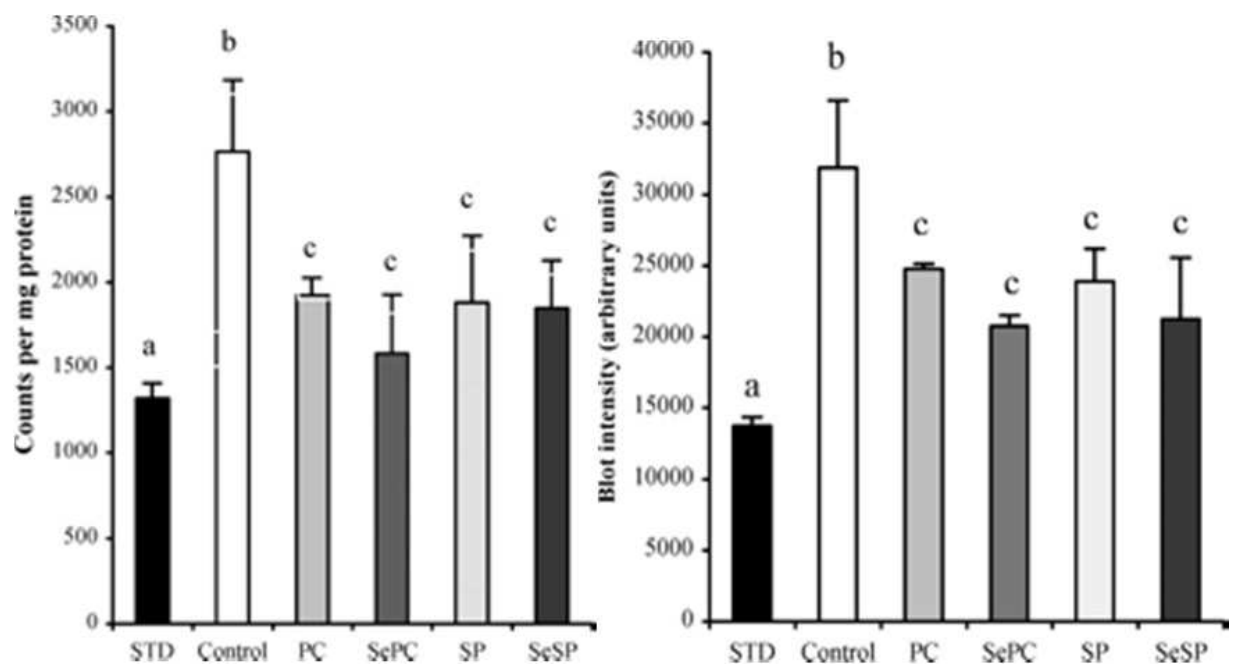

Fig. 13. Cardiac left ventricle superoxide anion production (left) measured by chemiluminescence probe (lucigenin $250 \mu \mathrm{M}$ ) and expression of cardiac p22phox subunit of $\mathrm{NAD}(\mathrm{P}) \mathrm{H}$ oxidase (right) in hamsters fed a standard diet (STD), in controls fed an atherogenic diet for 12 weeks, and in hamsters receiving an atherogenic diet plus phycocyanin (PC), Se-rich phycocyanin (SePC), spirulina (SP), or Se-rich spirulina (SeSP). Values are expressed as mean \pm SEM of triplicate wells $(n=8)$. For each dietary treatment, bars with different index letters differ, $\mathrm{P}<0.05$.

The results indicate that chronic consumption of Se-rich spirulina phycocyanin powerfully prevents the development of atherosclerosis. The underlying mechanism is related mainly to inhibiting pro-oxidant factors and at a lesser extent improving the serum lipid profile.

\subsection{Algal and fungal polysaccharides}

The postulated involvement of lipid peroxidation in atherogenesis invoked intensive research on antioxidants. Many compounds, from natural sources, newly synthesised derivatives of these compounds, and common drugs, were tested for their potency to inhibit the peroxidation of plasma lipids induced by different oxidants in vitro (Rice-Evans et al., 1996) to reduce the plaque formation in animal models in vivo (Barwicz et al., 2000) and to reduce the morbidity and mortality in human subjects, in clinical trials (Aviram et al., 2000). Indeed, mortality from cardiovascular disease is the leading cause of death in the industrialised world. Diet is believed to play a major role in the development of this disease, and much research is being focused on identifying ways to prevent it through changes in dietary habits. Oxidation of low-density lipoproteins (LDL) is traditionally accepted as 
initiating processes leading to the development of atherosclerosis. The earliest events in the development of the pathology are endothelial dysfunction and oxidative stress in the vascular cell wall, activation of inflammatory cells, and migration of vascular smooth muscle cells to the intima with the modification of the extracellular matrix, leading to the artery remodelling. Development of atherosclerosis is thought to be closely dependent upon increased oxidative stress, that is, an imbalance between ROS generation (chiefly superoxide anions, hydrogen peroxide, hydroxyl radicals) and natural cell antioxidant capacity in favour of the former (Frei, 1994). ROS can also regulate many signalling pathways, such as infiltration of monocytes in intima and vascular smooth muscle cell proliferation. A potentially important clinical corollary of the atherosclerosis oxidation theory is that inhibition of LDL oxidation may also inhibit atherosclerosis independent of lowering plasma cholesterol concentrations. Thus, it is essential to develop and utilise effective and natural antioxidants so that they can protect the human body from free radicals and retard the progress of many chronic diseases. Published data indicate that plant polysaccharides in general have antioxidant activities and can be explored as novel potential antioxidants $(\mathrm{Ng}$ et al., 2004; Jiang et al., 2005; Wang et al., 2007). Different polysaccharide fractions extracted and purified from litchi fruit pericarp tissues exhibited strong antioxidant activities (Yang et al., 2006). Tea polysaccharides were also shown to exert significant inhibitory effects on hydroxyl and superoxide radicals and lipid peroxidation. They could also improve the activity of superoxide dismutase. These results suggested that tea polysaccharides were potent antioxidants in mice (Chen et al., 2007). In addition, polysaccharides extracted from mushrooms, such as Auricularia auricular, have also shown antioxidant properties as shown by their free radical scavenging ability (Fan et al., 2007). The structure and mechanisms of the pharmaceutical effects of bioactive polysaccharides on diseases have been extensively studied, and more natural polysaccharides with different curative effects have been tested and even applied in therapies. Macroalgae have also received much attention as potential natural antioxidants (Duan et al., 2006). Thus, the antioxidant activity of natural polysaccharides from the green alga Ulva pertusa was determined in vitro, including scavenging activity against superoxide and hydroxyl radicals, reducing power, and chelating ability. They showed strong scavenging activity against hydroxyl radical and chelating ability (Qi et al., 2006).

Since Golden Syrian hamsters fed a fat-rich diet develop dyslipidemia and atherosclerotic plaques, similar in many respects to human atheroma (Nicolle et al., 2004; Auger et al., 2005 a), they were selected for a study in which we investigated the effects of Ulva, before and after processing (Godard et al., 2009). Three groups of 12 hamsters were fed a high cholesterol diet for $12 \mathrm{wk}$ (Control) or a high cholesterol diet where cellulose has been replaced for an equivalent fibre weight from Ulva or processed Ulva. Plasma cholesterol, non-HDL cholesterol and specially triglycerides were reduced by Ulva. Liver glutathione peroxidase activity was increased and thiobarbituric acid reactive substances were efficiently reduced by dietary treatments compared with controls, whereas plasma antioxidant capacity was increased (Table 9), cardiac $\mathrm{O}_{2}^{\circ}$ - production decreased by $41 \%$ (Ulva) and by $31 \%$ (processed Ulva) (Figure 14) and aortic fatty streak area was decreased by $70 \%$ as compared to controls, according to the same pattern observed for TBARS (Figure 15). 


\begin{tabular}{|c|c|c|c|}
\hline & Control & Ulva & Processed Ulva \\
\hline \multicolumn{4}{|l|}{ Plasma } \\
\hline $\mathrm{TC}^{1}, \mathrm{mmol} / \mathrm{L}$ & $7.77 \pm 0.31^{a}$ & $6.65 \pm 0.39 b$ & $7.30 \pm 0.19 a \mathrm{a}$ \\
\hline $\mathrm{HDLC}^{2}, \mathrm{mmol} / \mathrm{L}$ & $5.18 \pm 0.07 a$ & $5.04 \pm 0.12^{a}$ & $4.65 \pm 0.14^{a}$ \\
\hline Non HDLC, $\mathrm{mmol} / \mathrm{L}$ & $2.59 \pm 0.21 \mathrm{a}$ & $1.63 \pm 017 b$ & $2.65 \pm 0.17 \mathrm{a}$ \\
\hline $\mathrm{TG}^{3}, \mathrm{mmol} / \mathrm{L}$ & $1.76 \pm 012 \mathrm{a}$ & $0.89 \pm 0.10^{b}$ & $1.17 \pm 0.07 \mathrm{c}$ \\
\hline $\mathrm{PAC}, \mathrm{mmol} / \mathrm{L}$ & $0.81 \pm 0.05 \mathrm{a}$ & $1.35 \pm 0.05^{b}$ & $1.28 \pm 0.04^{b}$ \\
\hline \multicolumn{4}{|l|}{ Liver } \\
\hline $\mathrm{SOD}^{4}, \mathrm{U} / \mathrm{mg}$ protein & $22.68 \pm 1.41^{a}$ & $21.32 \pm 0.911^{a}$ & $22.40 \pm 1.04 \mathrm{a}$ \\
\hline GSHPx $5 /$ /mg protein & $0.43 \pm 0.03 a$ & $0.69 \pm 0.13 b$ & $0.72 \pm 0.05^{b}$ \\
\hline TBARS, $U / m g$ protein & $27.05 \pm 3.27 \mathrm{a}$ & $.34 \pm 0.29 b$ & $3.87 \pm 0.61^{c}$ \\
\hline
\end{tabular}

Values are means \pm SEM, $n=12$. Means in a row with superscripts without a common letter differ, $\mathrm{P}<$ 0.05. ${ }^{1}$ Total cholesterol. ${ }^{2}$ High density lipoprotein cholesterol. ${ }^{3}$ Triglycerides. ${ }^{4}$ Superoxide dismutase. ${ }^{5}$ GSHPx: glutathione peroxidase.

Table 9. Effects of ingestion of Ulva and processed Ulva on plasma lipid concentrations and plasma antioxidant capacity (PAC) and on hepatic antioxidant enzyme activities and thiobarbituric acid reactive substances (TBARS) in hamsters fed an atherogenic dietfor 12 weeks.

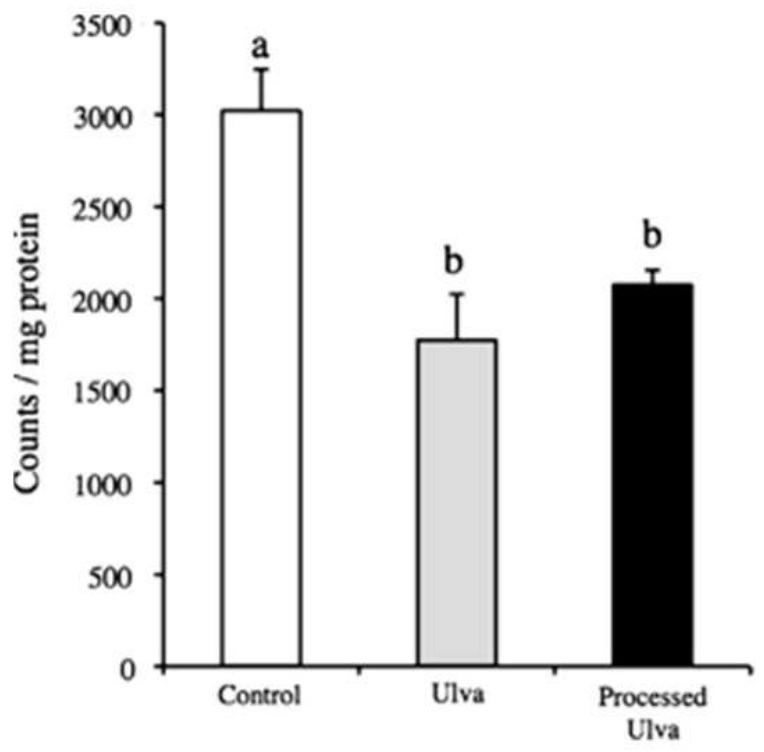

Fig. 14. Cardiac superoxide anion production in hamsters fed high cholesterol diet (control) or a high cholesterol diet where cellulose has been replaced for an equivalent fibre weight from Ulva or processed Ulva for 12 weeks. Values are expressed as mean \pm SEM of triplicate wells $(n=6)$. For each dietary treatment, bars with different index letters differ $(P<0.05)$. 


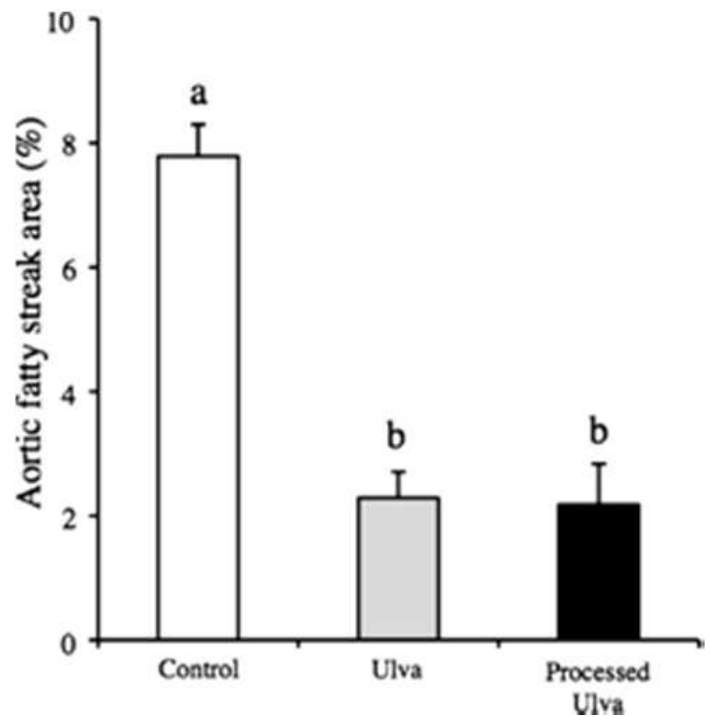

Fig. 15. Effects of feeding a high cholesterol diet (control) or a high cholesterol diet where cellulose has been replaced for an equivalent fibre weight from Ulva or processed Ulva on aortic fatty streak area in hamsters for 12 weeks. Values are expressed as mean \pm SEM $(n=$ $6)$. For each dietary treatment, bars with different index letters differ $(\mathrm{P}<0.05)$.

The results show for the first time that chronic consumption of polysaccharides supplied by Ulva prevent the fall of antioxidant defences and the development of atherosclerosis in hamsters. The underlying mechanism is related mainly to increased antioxidant status although improvement of the serum lipid profile was not ruled out.

We have also investigated the effects of chitin-glucan (CG) on early atherosclerosis, cardiac production of superoxide anion, and hepatic antioxidant enzymes in the hamster model of atherosclerosis (Berecochea-Lopez et al., 2009). Three groups of 12 hamsters were fed an atherogenic diet for 12 weeks. They received by gavage either water (control group) or CG

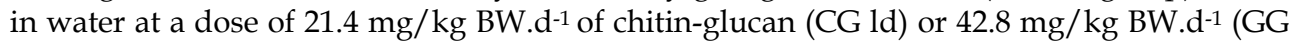
hd). CG did not affect plasma cholesterol but lowered triglycerides. It also strongly reduced the area of aortic fatty streak deposition by $87-97 \%$, cardiac production of superoxide anion by $25 \%$ (Figure 16), and liver MDA by $77-85 \%$, and enhanced liver superoxide dismutase activity by $7-45 \%$ and glutathionne peroxidase activity by $38-120 \%$ (Table 10). These findings support the view that chronic consumption of chitin-glucan has potential beneficial effects with respect to the development of atherosclerosis. The underlying mechanism is related mainly to improving the antioxidant status.

\subsection{Melon juice extract rich in superoxide dismutase activity}

Dietary factors are thought to play a key role in the regulation of the oxidant status. An imbalance between nutrients, and in particular those involved in antioxidant status, could explain the onset of an enhanced production of free radicals. A diet low in antioxidants contributes to the occurrence of an oxidative stress. The importance of dietary antioxidants 

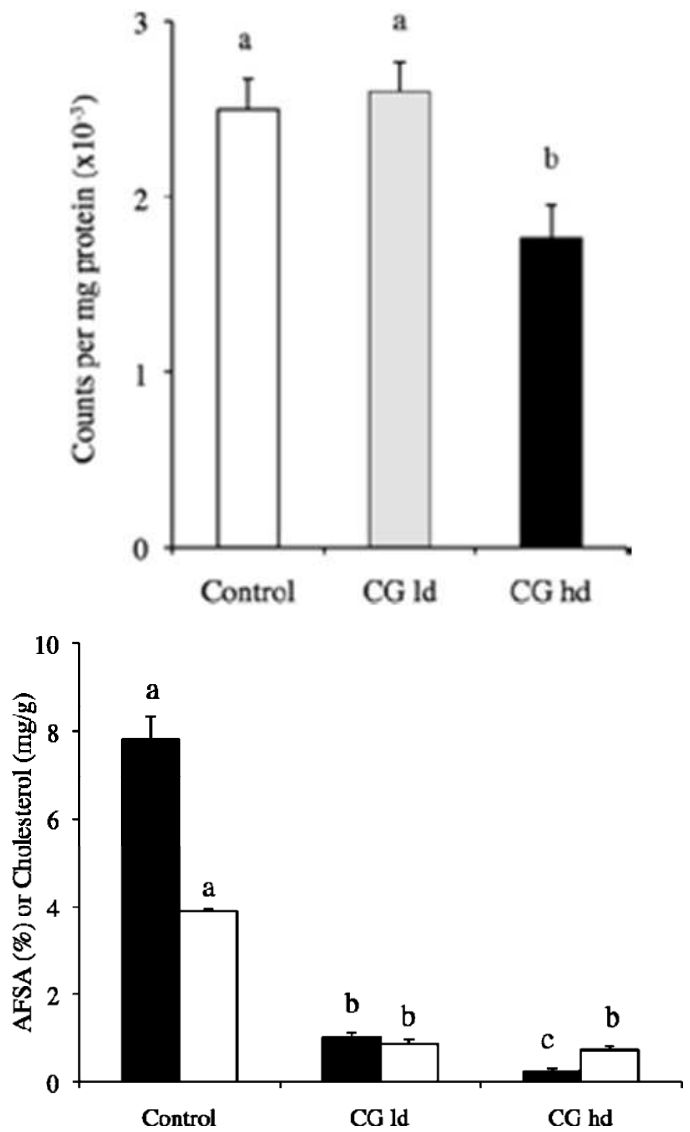

Fig. 16. Cardiac superoxide anion production (left) and aortic fatty streak area (AFSA, black bars) and aortic cholesterol level (white bars) (right) in hamsters fed an hyperlipidic diet without (Control) or with chitin-glucan at low dose (CG ld, $21.4 \mathrm{mg} / \mathrm{kg} \mathrm{BW.d}{ }^{-1}$ ) and high

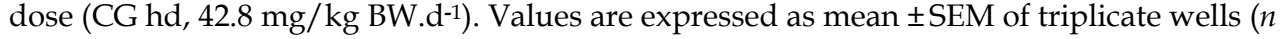
$=6)$. For each dietary treatment, bars with different index letters differ $(P<0.05)$.

\begin{tabular}{cccc}
\hline & Controls & CG ld & CG hd \\
\hline & & units.mg protein & \\
SOD $^{2}$ & $42 \pm 2^{\mathrm{a}}$ & $45 \pm 2^{\mathrm{a}}$ & $61 \pm 4^{\mathrm{b}}$ \\
$\mathrm{GSHPx}^{3}\left(\mathrm{x} \mathrm{10} 0^{-2}\right)$ & $1.55 \pm 0.32^{\mathrm{a}}$ & $2.14 \pm 0.11^{\mathrm{b}}$ & $3.42 \pm 0.42^{\mathrm{c}}$ \\
& & ng.mg protein & \\
TBARS & $27.05 \pm 3.27^{\mathrm{a}}$ & $6.11 \pm 0.39 \mathrm{~b}$ & $4.07 \pm 0.33^{\mathrm{c}}$ \\
\hline
\end{tabular}

1 Values are the means $\pm S E M ; n=12$. For each dietary treatment, means in a column with different superscripts differ, $\mathrm{P}<0.05$. 2 SOD: superoxide dismutase. 3 GSHPx: glutathione peroxidase.

Table 10. Hepatic antioxidant enzyme activities and thiobarbituric acid reactive substances (TBARS) in hamsters fed a hyperlipidic diet plus a daily gavage of water (Controls) or Chitin-Glucan at a low dose (CG ld) or Chitin-Glucan at a high dose (CG hd) ${ }^{1}$. 
in human health is clear and some epidemiological studies showed the potential health benefits of the consumption of antioxidant rich fruits and vegetables (Dauchet et al., 2006). From a theoretical point of view, antioxidant enzymes could exhibit a major advantage over dietary antioxidants known as micronutrients and microconstituents: they catalyse the detoxification of their substrates (Nelson et al., 2006) whereas the latter are consumed by reacting with ROS. New approaches to antioxidant therapy appeared recently. Nelson et al. (2006) reported that ingestion of an extract of five medicinal plants Protandim by healthy humans increased the circulating superoxide dismutase (SOD) and catalase activities and reduced the levels of thiobarbituric acid reactive-substances (TBARS), a marker of lipid peroxidation that correlates with oxidative stress and atherosclerosis (Rosenblat et al., 2006). Glisodin $\AA$, a melon juice concentrate coated with gliadin containing high levels of SOD and other antioxidant enzymes, has been developed and its antioxidant properties have been demonstrated (Vouldoukis et al., 2004 a). Given to mice, it exhibited properties similar to Protandim (Vouldoukis et al., 2004 b) leading up to a fourfold increase of circulating and hepatic tissue antioxidant enzyme activities. In healthy volunteers, oral Glisodin ${ }^{\circledR}$ was associated with less lipid peroxidation (Muth et al., 2004). Very recently, these authors demonstrated that a pre-treatment with Glisodin ${ }^{\circledR}$ may be a therapeutic option to reduce oxidative cell injury affiliated with aortic cross-clamping in pigs (Kick et al., 2007). Thus, we investigated whether feeding a melon juice concentrate rich in superoxide dismutase and coated with palm oil (Extramel®) to hamsters on an atherogenic diet (HF) would prevent the development of the pathology (Décordé et al., 2010). Hamsters received by gavage either water or Extramel® at $0.7,2.8$ or $5.6 \mathrm{mg} / \mathrm{d}$. After $12 \mathrm{wk}$ of oral administration, Extramel ${ }^{\circledR}$ lowered plasma cholesterol and non-HDL cholesterol and induced blood and liver SOD activities. It also strongly reduced the area of aortic fatty streak (AFSA) by $49-85 \%$ (Table 11).

\begin{tabular}{|c|c|c|c|c|c|}
\hline & STD & $\mathrm{HF}$ & E1 & E2 & E3 \\
\hline \multicolumn{6}{|l|}{ Plasma } \\
\hline $\mathrm{TC}^{1}, \mathrm{mmol} / \mathrm{L}$ & $2.06 \pm 0.09$ & $9.22 \pm 2.46^{\mathrm{a}}$ & $7.25 \pm 2.09 \mathrm{ab}$ & $4.62 \pm 1.43^{b}$ & $4.98 \pm 1.33^{b}$ \\
\hline $\mathrm{HDLC}^{2}, \mathrm{mmol} / \mathrm{L}$ & $1.42 \pm 0.64$ & $4.97 \pm 1.33^{a}$ & $4.33 \pm 1.28^{\mathrm{a}}$ & $2.56 \pm 0.85^{\mathrm{a}}$ & $2.69 \pm 1.28^{a}$ \\
\hline $\begin{array}{c}\text { Non HDLC, } \mathrm{mmol} / \mathrm{L} \\
\text { Liver }\end{array}$ & $0.64 \pm 0.03$ & $4.25 \pm 1.13^{\mathrm{a}}$ & $2.92 \pm 0.8^{\mathrm{a}}$ & $1.66 \pm 0.58 \mathrm{~b}$ & $2.29 \pm 0.05^{b}$ \\
\hline $\mathrm{SOD}, \mathrm{IU} / \mathrm{mg}$ prot & $21.9 \pm 1.4$ & $18.8 \pm 1.5^{\mathrm{a}}$ & $20.7 \pm 0.7 \mathrm{a}$ & $20.2 \pm 0.7^{a}$ & $45.1 \pm 4.6^{b}$ \\
\hline $\begin{array}{c}\mathrm{GSHPx}, \mathrm{IU} / \mathrm{mg} \text { prot } \\
\text { Aorta }\end{array}$ & $2190 \pm 120$ & $2097 \pm 102^{a b}$ & $2517 \pm 125^{a}$ & $1640 \pm 156^{b}$ & $2401 \pm 284^{a}$ \\
\hline AFSA, $\%$ & 0 & $5.8 \pm 0.5^{\mathrm{a}}$ & $2.6 \pm 0.5^{b}$ & $1.9 \pm 0.4^{\mathrm{b}}$ & $1.1 \pm 0.3^{c}$ \\
\hline
\end{tabular}

Table 11. Effect of feeding a standard diet (STD) or high fat diet (HF), or an HF diet plus Extramel $^{\circledR}$ at 0.7 (E1), 2.8 (E2) or 5.6 (E3) mg/d for 12 weeks on blood lipids, on liver antioxidant enzymes superoxide dismutase (SOD) and glutathion peroxidase (GSHPx) activities, and on aortic fatty streak area (AFSA).

Values are means \pm SEM $(n=12)$. For each dietary treatment, means in a column with different superscripts differ, $\mathrm{P}<0.05 .{ }^{1} \mathrm{TC}=$ Total cholesterol, ${ }^{2} \mathrm{HDL}-\mathrm{C}=$ High density lipoprotein cholesterol.

Cardiac $(45 \%)$ and liver $(67 \%)$ production of superoxide anion and liver p22phox subunit of $\mathrm{NAD}(\mathrm{P}) \mathrm{H}$ oxidase expression $(66 \%)$ were also reduced (Figures 17 and 18). 


\section{Heart}
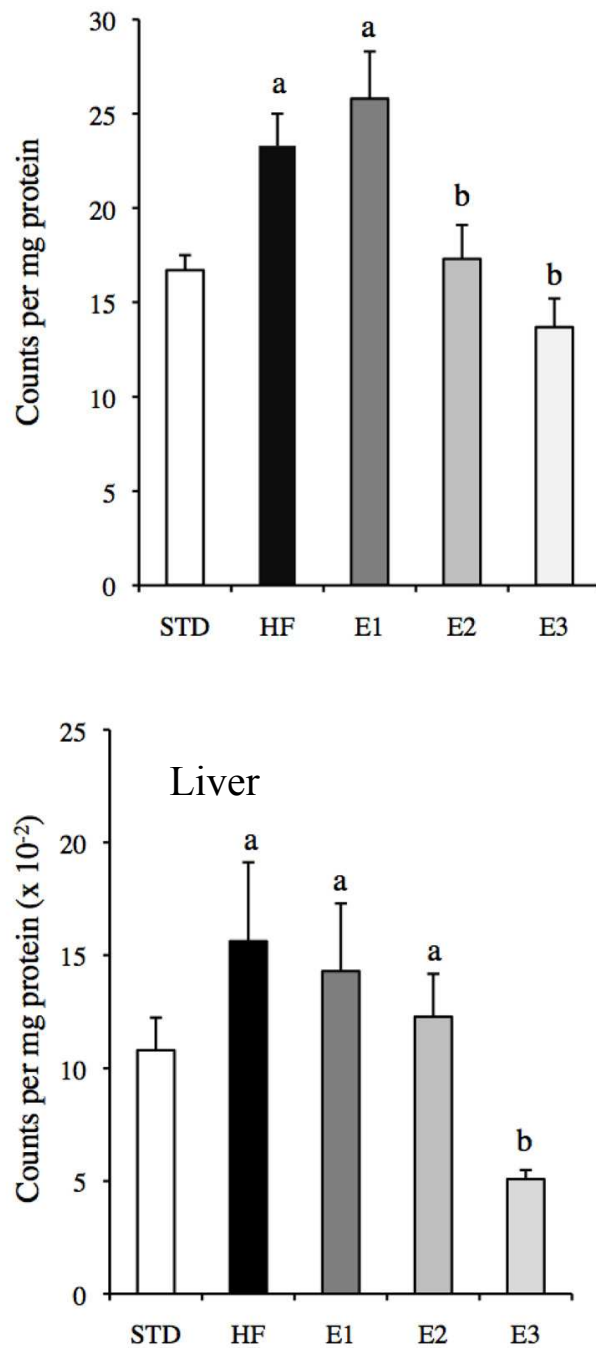

Fig. 17. Cardiac and liver superoxide anion production in hamsters fed a standard diet (STD) or a high fat diet (HF), or a HF diet plus Extramel ${ }^{\circledR}$ at 0.7 (E1), 2.8 (E2) or 5.6 (E3) $\mathrm{mg} / \mathrm{d}$ for 12 weeks. Values are expressed as mean \pm SEM $(n=12)$. For each dietary treatment, bars with different index letters differ $(P<0.05)$. 


\section{STD $\quad$ HF $\quad$ E1 $\quad$ E2 $\quad$ E3}

p22 phox

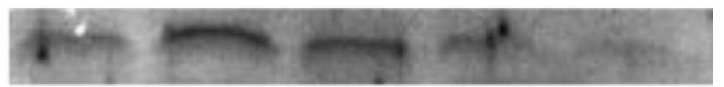

B-actin
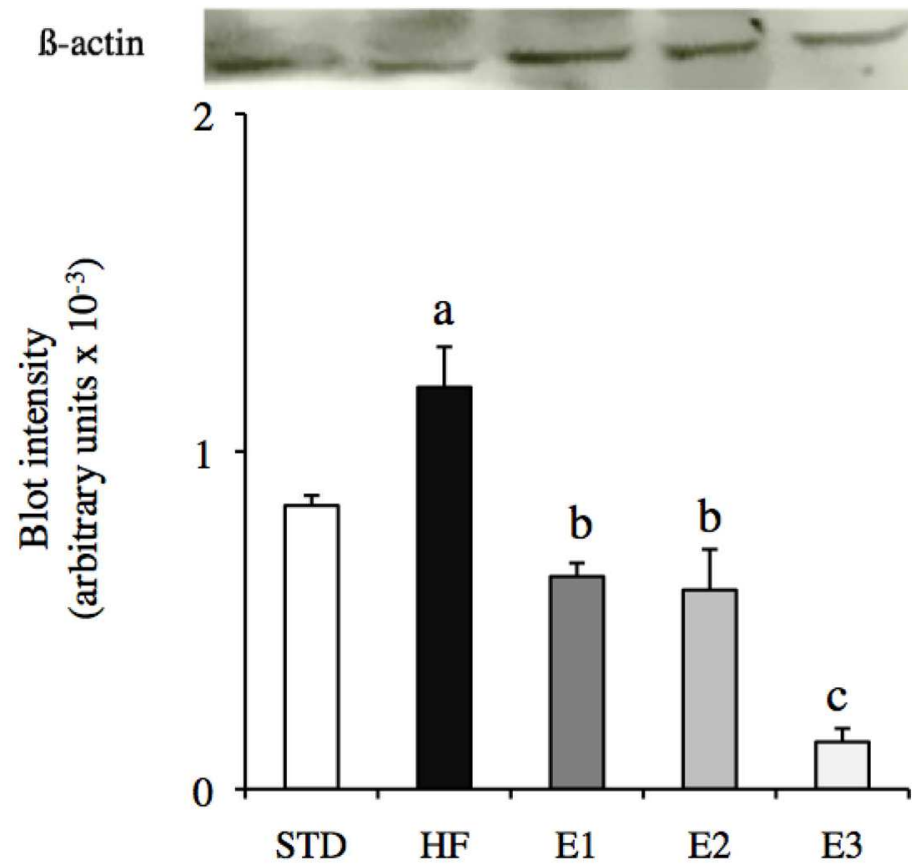

Fig. 18. Expression of hepatic p22phox subunit of $\mathrm{NAD}(\mathrm{P}) \mathrm{H}$ oxidase in hamsters fed with a standard diet (STD) or a high-fat diet (HF), or an HF diet plus Extramel ${ }^{\circledR}$ at 0.7 (E1), 2.8 (E2) or 5.6 (E3) mg/d for 12 weeks. The densitometric measurement shows arbitrary area units. Values are expressed as mean \pm SEM $(n=6)$. For each dietary treatment, bars with different index letters differ $(\mathrm{P}<0.05)$.

Finally, Extramel ${ }^{\circledR}$ attenuated the development of hepatic steatosis (Figure 19).

These findings support the view that chronic consumption of melon juice extract rich in SOD has potential beneficial effects with respect to the development of atherosclerosis and liver steatosis, emphasizing its use as potential dietary therapy. 


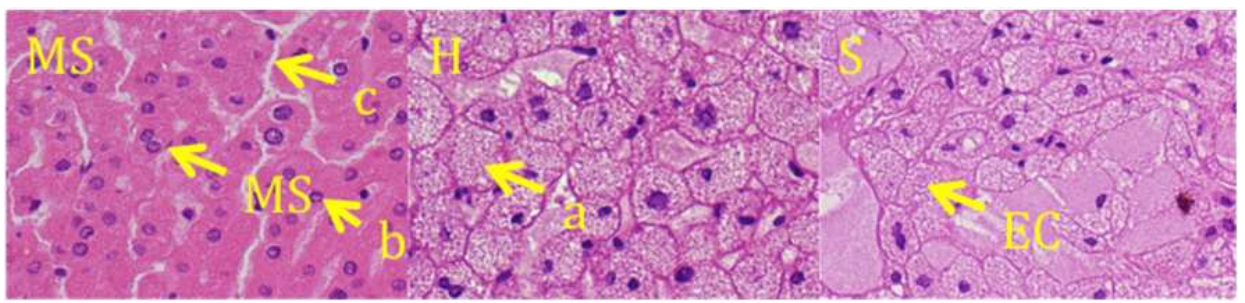

Fig. 19. Histologic evaluation of hepatic steatosis in standard (a), atherogenic (b) or Extramel ${ }^{\circledR}$ treated $(5.6 \mathrm{mg} / \mathrm{d}$ ) (c) hamsters for 12 weeks. Representative liver sections (original magnification $\times 200$ ) are illustrated. (a) Liver section from a hamster fed the standard diet. (b) Atherogenic hamster fed no Extramel ${ }^{\circledR}$ illustrate the development of hepatic steatosis. (c) Slight reduction in hepatic steatosis in $5.6 \mathrm{mg} / \mathrm{d}$ Extramel fed hamsters. Sinusoidal capillary (S) ; Endothelial cell (EC) ; Hepatocyte (H) ; Microvascular steatosis (MS).

\section{Preventive effects of dietary antioxidants against obesity}

\subsection{Chardonnay grape seed procyanidin extract}

According to the International Obesity Task Force, an estimated 300 millions adults worldwide are obese. Obesity, particularly that caused by visceral fat accumulation, is an important risk factor for sedentary lifestyle-related diseases, such as type 2 diabetes mellitus, coronary heart diseases and cerebrovascular events, hyperlipidemia, hypertension, and cancer (Braddon et al., 1986; Esposito et al., 2003; Mokdad et al., 2003). Oxidative stress could be a potential link between fat accumulation and obesity-related morbidity such as diabetes and cardiovascular diseases. Indeed, this pathology can contribute to an increased susceptibility to ROS. In the general population, several groups at risk of high oxidative stress are identified and more particularly the obese subjects, in relation to reduced antioxidant defenses and/or a strong free radicals production.

High fat-feeding has commonly been used to induce visceral obesity in rodent animal models (Hansen et al., 1997) because of the similar pathogenesis of obesity to that found in humans (Katagiri et al., 2007). Preventive or therapeutic strategies to control most of human obesity should target these abnormalities. Anti-obesity foods and food ingredients may avert the condition, possibly leading to the prevention of lifestyle-related diseases, if they are effective in reducing the visceral fat mass (Saito et al., 2005). It has been reported that the body weights of rats and their plasma triglycerides, cholesterol and LDL-cholesterol have been significantly reduced by feeding Oolong, black, and green tea leaves. Epigallocatechin gallate (EGCG) purified from green tea when given to mice in diet decreased diet-induced obesity by decreasing energy absorption and increasing fat oxidation (Klaus et al., 2005). Supplementation with tea catechins resulted in a significant reduction of high-fat dietinduced body weight gain, adipose tissue mass, liver fat content, and the development of hyperinsulinemia and hyperleptinemia in C57BL/6J mice (Murase et al., 2002). Recently the continuous ingestion of a green tea extract high in catechins by humans led to a reduction in body fat, systolic blood pressure, and LDL cholesterol, suggesting that the ingestion of such an extract contributes to a decrease in obesity and cardiovascular disease risks (Nagao et al., 2007). More recently, Wolfram et al. (2005) showed that supplementation with Teavigo ${ }^{\circledR}$, a green tea extract containing about 94\% EGCG, abolishes diet-induced obesity and claimed that this was a valuable natural treatment option for obesity. Nakagawa et al. (2004) 
demonstrated the abdominal fat lowering and hypoglycemic effects of licorice hydrophobic flavonoids in obese diabetic mice and elucidated their mechanisms of action by showing that they induce differentiation of human adipocytes. Sugiyama et al. (2007) suggested that oligomeric procyanidin was the main contributor to the effect of apple polyphenol extract on inhibiting triglyceride absorption in mice and humans. Apple procyanidins may relieve obesity via a lipase inhibiting activity and may be effective for obesity-related diseases. To our knowledge, the antiobesity effects of grape seed catechins have not been examined yet. Only Vadillo et al. (2006) showed that moderate red wine intake can prevent the increase of body weight by modulating energy intake in a rat diet-induced model of obesity. The present study was designed to examine the preventive effect of a grape seed tannin extract (GSE) on the development of obesity induced by feeding a HF diet in hamsters. Feeding hamsters a cholesterol-supplemented diet produces dyslipidemia (Nistor et al., 1987). This model was also chosen because hamsters have a plasma lipoprotein distribution similar to that of humans. It has been also used by Simon et al. (2006) and developed obesity traits, and Leung et al. (2004) showed that the fat-fed Syrian Golden hamster is a good model of nutritionally induced insulin resistance. Elsewhere, GSE is a rich source of $(+)$-catechin, $(+)-$ epicatechin and procyanidins (Prieur et al., 1994). Keaney et al. (2003) reported that obesity is a strong independent predictor of systemic oxidative stress and suggested that obesity is associated with a state of excess oxidative stress. As one of the possible mechanisms of the obesity-related oxidative stress, we also examined the modulation by HF diet (with or without GSE) of cardiac production of superoxide anions and $\mathrm{NAD}(\mathrm{P}) \mathrm{H}$ oxidase expression.

We have analyzed the effects of a polyphenolic grape seed extract (GSE) on obesity and oxidative stress in hamsters receiving a high-fat diet (HF) (Décordé et al., 2009 a). Three groups of hamsters received a standard diet, or a HF diet plus a daily gavage with water (Control, HF) or a solution of GSE (HF+GSE). After 12 weeks, HF diet increased abdominal fat as compared with standards. GSE avoided this feature. HF diet led to higher plasma glucose, triglycerides, insulin and greater insulin resistance (HOMA-IR) values. GSE prevented in part these effects, reducing insulinemia and leptinemia by $16.5 \%$ and $45 \%$ respectively, whereas adiponectin level increased by $61 \%$ compared with obese controls. GSE lowered glycemia and HOMA-IR (Table 12) and strongly prevented cardiac production of superoxide by $74 \%$ and $\mathrm{NAD}(\mathrm{P}) \mathrm{H}$ oxidase expression by $30 \%$ (Table 13 ).

\begin{tabular}{cccc}
\hline & STD & HF & HF+GSE \\
\hline Body weight gain, $g$ & $14 \pm 3^{\mathrm{c}}$ & $38 \pm 2^{\mathrm{a}}$ & $25 \pm 2^{\mathrm{b}}$ \\
Abdominal white fat, & $1.19 \pm 0.11^{\mathrm{c}}$ & $2.20 \pm 0.12^{\mathrm{a}}$ & $1.55 \pm 0.03^{\mathrm{b}}$ \\
$\% \mathrm{BW}$ & $0.97 \pm 0.09^{\mathrm{b}}$ & $3.14 \pm 0.33^{\mathrm{a}}$ & $2.76 \pm 0.19 \mathrm{a}$ \\
Triglycerides, $\mathrm{mmol} / \mathrm{L}$ & $4.76 \pm 0.41^{\mathrm{c}}$ & $6.85 \pm 0.44^{\mathrm{a}}$ & $5.57 \pm 0.37^{\mathrm{b}}$ \\
Glucose, $m m o l / L$ & $0.27 \pm 0.02^{\mathrm{b}}$ & $0.66 \pm 0.07 \mathrm{a}$ & $0.55 \pm 0.07 \mathrm{a}$ \\
Insulin, $n g / m L$ & $37.79 \pm 3.02^{\mathrm{c}}$ & $132.95 \pm 11.24^{\mathrm{a}}$ & $90.06 \pm 8.66^{\mathrm{b}}$ \\
HOMA-IR & $1.52 \pm 0.09^{\mathrm{b}}$ & $2.63 \pm 0.22^{\mathrm{a}}$ & $1.45 \pm 0.23^{\mathrm{b}}$ \\
Leptin, $n g / m L$ & $3.11 \pm 0.12^{\mathrm{a}}$ & $1.43 \pm 0.15^{\mathrm{c}}$ & $2.26 \pm 0.20^{\mathrm{b}}$ \\
\hline Adiponectin, $n g / m L$ & & & \\
\hline
\end{tabular}

Table 12. Effects of a grape seed extract (GSE) consumption on body weight, food and energy intakes, and plasma glucose, triglycerides, insulin, leptin and adiponectin of hamsters fed a standard diet (STD), a high fat diet (HF) or a high fat diet plus a grape seed extract (HF+GSE) for 12 weeks. 
Plasma glucose, triglycerides, insulin, leptin and adiponectin were measured at the fasted state at the end of the 12-week treatment period. HOMA-IR : homeostatic model assessment for insulin resistance. Values are means $\pm \mathrm{SEM}, n=14$. Means in a row with superscripts without a common letter differ, $P<0$.

\begin{tabular}{cccc}
\hline & STD & HF & HF+GS \\
\hline $\mathrm{O}_{2}{ }^{\circ}$, counts $/ m g$ protein & $520 \pm 30^{\mathrm{a}}$ & $896 \pm 140^{\mathrm{b}}$ & $229 \pm 45^{\mathrm{c}}$ \\
$\begin{array}{c}\mathrm{NADP}(\mathrm{H}) \text { oxidase } \\
\text { expression }\end{array}$ & $5.5 \pm 0.7^{\mathrm{a}}$ & $20.4 \pm 1.8^{\mathrm{b}}$ & $14.3 \pm 1.3^{\mathrm{c}}$ \\
\hline
\end{tabular}

${ }^{1}$ Values are means \pm SEM $(n=14)$. Means in a row with superscripts without a common letter differ, $P<$ 0.05 .

${ }^{2}$ Blot intensity expressed as arbitrary units $\times 10^{-3}$

Table 13. Cardiac superoxide anion production $\left(\mathrm{O}_{2}{ }^{\circ}-\right)$ and expression of $\mathrm{NADP}(\mathrm{H})$ oxidase p22phox subunit in hamsters fed a standard diet (STD) or a high fat diet without (HF) or with a grape seed extract (HF+GSE) for 12 weeks¹.

This is the first time that chronic consumption of grape phenolics is shown to reduce obesity development and related metabolic pathways including adipokine secretion and oxidative stress.

\subsection{Melon juice extract rich in superoxide dismutase activity}

High-fat diets and sedentary lifestyles are important risk factors for obesity which is a key feature of metabolic syndrome and which greatly predisposes individuals to liver diseases, cardiovascular disease, type 2 diabetes, dyslipidemia, hypertension and numerous cancers and is associated with markedly diminished life expectancy (Haslam \& James, 2005).

We previously investigated a hamster model of diet-induced obesity and insulin resistance that exhibits oxidative stress and some correlates to human obesity (Luft \& Landau, 1995). A close correlation has been found between increased oxidative stress in accumulated fat and the pathogenic mechanism of obesity and obesity-associated metabolic syndrome, and Keaney et al. (2003) reported that obesity is a strong independent predictor of systemic oxidative stress, suggesting that obesity is associated with a state of excess oxidative stress. This may be the source of several metabolic dysfunctions like inflammation, hypertension, and impaired glucose intake in muscle and fat, which are highly related to obesity. Oxidative stress could be a potential link between fat accumulation and obesity-related morbidity such as diabetes and cardiovascular diseases. Indeed, this pathology can contribute to an increased susceptibility to ROS. In the general population, several groups at risk of high oxidative stress are identified and more particularly the obese subjects, in relation to reduced antioxidant defences and/or a strong free radicals production.

Of the many potential cellular sources of chronic ROS production, mitochondria and nonphagocytic $\mathrm{NAD}(\mathrm{P}) \mathrm{H}$ oxidase are the major sources under physiological conditions (Wallace, 1999; Sorescu \& Griendling, 2002). Increased mitochondrial ROS generation and dysfunction are associated with cardiovascular and many other diseases (Yamauchi et al., 2001). Elsewhere, adipocytes synthesize and secrete adipocytokines. Dysregulated production of these adipocytokines participates in the pathogenesis of obesity-associated metabolic syndrome. Among them, adiponectin exerts insulin-sensitizing (Okamoto et al., 
2002) and anti-atherogenic effects (Ozata et al., 2002), and hence a decrease in plasma adiponectin is causative for insulin resistance and atherosclerosis in obesity. However, obesity has been shown to be one of the conditions that decrease antioxidant capacity (Carmiel-Haggai et al., 2005), and it seems to accomplish this by lowering the levels of antioxidant enzymes (catalase, glutathione peroxidase, and glutathione reductase) (Furukawa et al., 2004). In animal (Carmiel-Haggai et al., 2005) and human studies (Furukawa et al., 2004), obesity is associated with a decrease in tissue or plasma antioxidant capacity. In obese mice, treatment with $\mathrm{NAD}(\mathrm{P}) \mathrm{H}$ oxidase inhibitor reduced ROS production in adipose tissue, attenuated the dysregulation of adipocytokines and improved (Ozata et al., 2002) diabetes, hyperlipidemia, and hepatic steatosis. Since obesity may induce systemic oxidative stress, increased oxidative stress should be an important target for the development of new therapies. Generally, dietary antioxidants are vitamins, fibers and phytochemicals supplied by fruits and vegetables. Recently, much attention has been focused on new approaches of antioxidant therapy by providing antioxidant enzymes. Thus, a melon juice concentrate containing high levels of superoxide dismutase (Lacan \& Baccou, 1998) and other antioxidant enzymes has been developed and its antioxidant and anti-inflammatory properties have been demonstrated (Vouldoukis et al., 2004 a). This melon concentrate combined with wheat gliadin polymer, called Glisodin ${ }^{\circledR}$, was given for 4 weeks to mice, reducing the levels of thiobarbituric acid reactive-substances, a marker of lipid peroxidation that correlates with oxidative stress and leading up to a fourfold increase of circulating and hepatic tissue antioxidant enzyme activity (SOD and catalase) (Vouldoukis et al., 2004 b).

Studies showed that dietary antioxidants could be a therapy against obesity that is associated with a state of oxidative stress. In this context, we undertook a study designed to quantitatively examine the properties of Extramel ${ }^{\circledR}$ microgranules, a melon juice extract coated with palm oil and rich in antioxidants and particularly SOD, on the development of obesity in our golden Syrian hamster model of diet-induced obesity (Décordé et al., 2009 b). Five groups received a standard diet, or a high fat diet $(\mathrm{HF})$ plus a daily gavage with water (Control) or extract at $0.7,2.8$ or $5.6 \mathrm{mg} /$ day. After 84 days, the higher dose lowered triglyceridemia $(68 \%)$, production of liver superoxide anion (12\%), leptinemia (99\%) and increased adiponectinemia (29\%), leading to a concomitant reduction in insulinemia (39\%), insulin resistance $(41 \%)$ and abdominal lipids (25\%) and a remarkable decrease of liver lipids (73\%) (Tables 14 and 15).

\begin{tabular}{cccccc}
\hline & SD & HF & E1 & E2 & E3 \\
\hline Body weight gain, $g$ & $30.1 \pm 1.0$ & $44.8 \pm 2.0$ & $32.1 \pm 1.8^{\mathrm{a}}$ & $31.6 \pm 2.3^{\mathrm{a}}$ & $31.7 \pm 1.6^{\mathrm{a}}$ \\
Abdominal fat, $\% \mathrm{BW}$ & $1.10 \pm 0.07$ & $1.34 \pm 0.04$ & $1.22 \pm 0.01^{\mathrm{a}}$ & $1.14 \pm 0.05^{\mathrm{a}}$ & $1.00 \pm 0.03^{\mathrm{a}}$ \\
Plasma & & & & & \\
Triglycerides, $m m o l / L$ & $0.87 \pm 0.08$ & $6.29 \pm 0.53$ & $6.71 \pm 0.18$ & $1.90 \pm 0.03^{\mathrm{a}}$ & $2.05 \pm 0.07 \mathrm{a}$ \\
Glucose, $m m o l / L$ & $5.43 \pm 0.42$ & $6.34 \pm 0.53$ & $5.75 \pm 0.47$ & $6.55 \pm 0.51$ & $6.20 \pm 0.35$ \\
Insulin, $n g / m L$ & $0.33 \pm 0.08$ & $0.43 \pm 0.00$ & $0.34 \pm 0.07 \mathrm{a}$ & $0.33 \pm 0.04^{\mathrm{a}}$ & $0.26 \pm 0.02^{\mathrm{a}}$ \\
HOMA-IR & $52.7 \pm 2.0$ & $80.2 \pm 1.5$ & $57.5 \pm 1.0^{\mathrm{a}}$ & $63.5 \pm 1.1^{\mathrm{a}}$ & $47.4 \pm 0.4^{\mathrm{a}}$ \\
Leptin, $n g / m L$ & $0.22 \pm 0.02$ & $0.40 \pm 0.05$ & $0.35 \pm 0.04$ & $0.29 \pm 0.04^{\mathrm{a}}$ & $0.28 \pm 0.04^{\mathrm{a}}$ \\
Adiponectin, $n g / m L$ & $7.30 \pm 1.70$ & $4.98 \pm 0.25$ & $5.65 \pm 0.40$ & $6.10 \pm 0.68$ & $6.40 \pm 0.36^{\mathrm{a}}$ \\
\hline
\end{tabular}

Table 14. Body weight, food and energy intake, plasma glucose, triglycerides, insulin, leptin and adiponectin in hamsters fed a standard diet (SD), a high fat diet (HF) or a HF diet plus Extramel ${ }^{\circledR}$ at $0.7 \mathrm{mg} / \mathrm{d}$ (E1), $2.8 \mathrm{mg} / \mathrm{d}$ (E2) or $5.6 \mathrm{mg} / \mathrm{d}$ (E3) on blood lipids for 12 weeks. Plasma glucose, triglycerides, insulin, leptin and adiponectin were measured at the fasted state at the end of the 12-week treatment period. HOMA-IR: homeostatic model assessment for insulin resistance. Values are means $\pm \operatorname{SEM}(n=12)$. a means $\mathrm{p}<0.05 \mathrm{vs} \mathrm{HF}$. 
Dietary Antioxidants: From Micronutrients and

\begin{tabular}{|c|c|c|c|c|c|}
\hline & SD & $\mathrm{HF}$ & E1 & E2 & E3 \\
\hline Lipids, $m g / g$ & $6.60 \pm 2.5$ & $21.31 \pm 1.60$ & $12.34 \pm 1.90^{\mathrm{a}}$ & $6.11 \pm 1.12^{a}$ & $5.73 \pm 0.61^{\mathrm{a}}$ \\
\hline GSH-Px ${ }^{1}, \mathrm{U} / \mathrm{mg}$ prot & $2191 \pm 380$ & $4397 \pm 590$ & $2980 \pm 268^{a}$ & $2912 \pm 314^{a}$ & $3588 \pm 590$ \\
\hline Cu-Zn-SOD, U/mg prot & $21.9 \pm 1.4$ & $31.6 \pm 2.3$ & $31.0 \pm 1.7$ & $32.6 \pm 2.0$ & $34.6 \pm 2.0$ \\
\hline Mn-SOD, U/mg prot & $3.26 \pm 0.06$ & $2.87 \pm 0.24$ & $3.35 \pm 0.17$ & $3.64 \pm 0.17^{\mathrm{a}}$ & $3.64 \pm 0.12^{\mathrm{a}}$ \\
\hline $\mathrm{TBARS}^{2}, \mathrm{mmol} / \mathrm{mg}$ prot & $6.19 \pm 1.5$ & $11.30 \pm 2.00$ & $8.96 \pm 1.95$ & $7.53 \pm 3.03$ & $7.39 \pm 1.40^{\mathrm{a}}$ \\
\hline $\mathrm{O}_{2}{ }^{\circ}$ - production ${ }^{3}$ & $1080 \pm 143$ & $1810 \pm 435$ & $1750 \pm 404$ & $1579 \pm 63^{a}$ & $1606 \pm 260$ \\
\hline
\end{tabular}

${ }^{1}$ Glutathion peroxidase. ${ }^{2}$ Thiobarbituric acid reactive substances. Values are means \pm SEM $(n=12)$. ${ }^{a}$ means $\mathrm{p}<0.05$ vs HF. ${ }^{3}$ Expressed as counts per mg protein.

Table 15. Liver lipids, oxidative status of hamsters fed a standard diet (SD) and NAD(P)Hdependent anion superoxide production in hamsters fed a high fat diet (HF) or a HF diet plus Extramel ${ }^{\circledR}$ at $0.7 \mathrm{mg} / \mathrm{d}(\mathrm{E} 1), 2.8 \mathrm{mg} / \mathrm{d}(\mathrm{E} 2)$ or $5.6 \mathrm{mg} / \mathrm{d}$ (E3) for 12 weeks.

The extract fully prevented the steatohepatitis induced by HF diet (Figure 20).
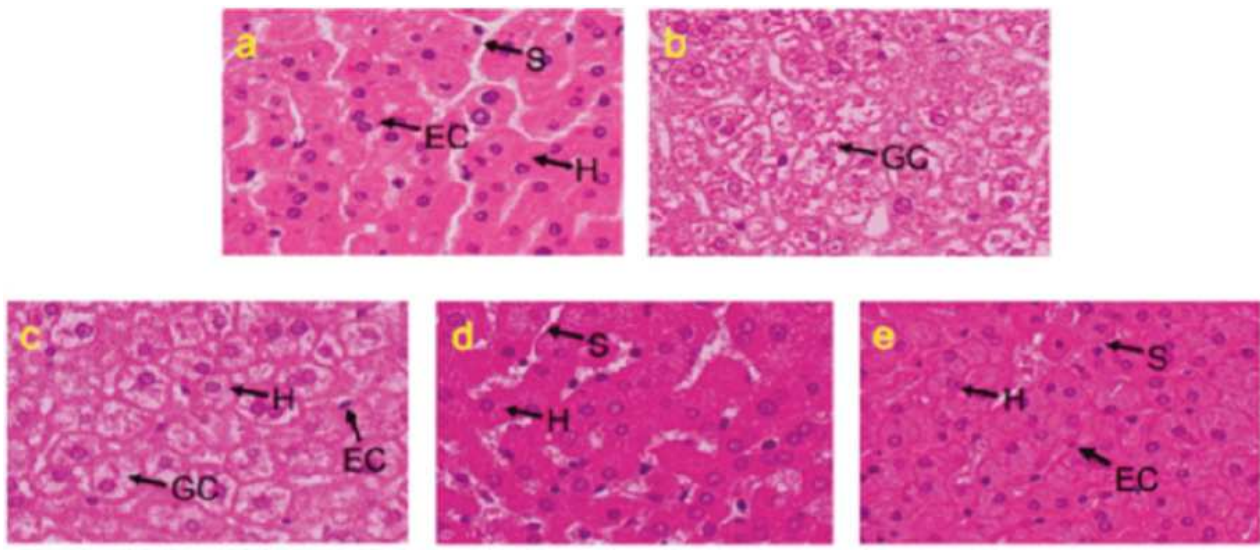

Fig. 20. Histologic evaluation of hepatic modifications in obese (b) or Extramel-treated hamsters (c, d, e) for 12 weeks. Representative liver sections (original magnification $x 200$ ) are illustrated. (a) Liver section from a hamster fed the standard diet. (b) Obese hamster fed no Extramel illustrates the development of hepatic ballooning degeneration. (c) No degeneration reduction after treatment with Extramel at $0.7 \mathrm{mg} / \mathrm{d}$. (d, e) Gradual improvement with Extramel at 2.8 and $5.6 \mathrm{mg} / \mathrm{d}$. Sinusoidal capillary (S); Endothelial cell (EC); Hepatocyte (H); Grainy fatty cytoplasm (GC).

These findings suggested that chronic consumption of melon extract may represent a new alternative to reduce the obesity induced by oxidative stress.

\section{Discussion}

Improvement of plasma lipid profile, increase in plasma antioxidant capacity (PAC), and decrease in superoxide anion production and reduction of $\mathrm{NAD}(\mathrm{P}) \mathrm{H}$ oxidase expression (p22phox subunit) by Oxxynea ${ }^{\circledR}$ were associated with a total prevention of aortic fatty streak lesion area. The relative contribution of each parameter such as lipid profile, plasma antioxidant defenses and overproduction of ROS is difficult to establish. However, it is 
tempting to speculate on a specific role of tissular oxidative stress. Indeed, in a previous paper, it has been shown that the wine polyphenols- induced aortic fatty streak lesion area prevention was associated with lipid and plasma antioxidant capacity improvement without any effect on plasma oxidative stress markers such as MDA (malondialdehyde), AOPP (Advanced oxidation protein products), and AGEs (An advanced glycation end-product) (Auger et et al., 2005 a). Taken together, these results suggest a specific role of polyphenol in vascular tissue mediated by $\mathrm{NAD}(\mathrm{P}) \mathrm{H}$ oxidase and that this extract acted by mechanisms operating both inside and outside a hypolipemic effect, especially an antioxidant effect. Although the constituent(s) responsible for these effetcs remain(s) unclear, candidates such as vitamin C, vitamin E, carotenoids, selenium, and polyphenols could act synergistically or additively to prevent atherosclerosis in the hamster model. The emphasized the complexity of numerous possible operating mechanisms of action depending on the presence and combination of different families of phenolic compounds, in both nature and quantity.

When fed daily to Syrian golden hamsters on an atherogenic diet for 12 weeks at a dose corresponding to the consumption of $275 \mathrm{~mL}$ by a $70 \mathrm{~kg}$ human, juices prepared from three varieties of raspberry, Cardinal, Glen Ample and Tulameen, lowered biomarkers of early atherosclerosis. Although the effects were not identical for all three juices, our findings suggest that moderate consumption of raspberry juices may help to prevent the development of early atherosclerosis, with the underlying mechanisms related to improved antioxidant status and serum lipid profiles. The main polyphenolic compounds in the juices were anthocyanins and ellagitannins, neither of which is likely to be absorbed into the bloodstream in sufficient quantity to induce the observed protective effects. The principal components entering the circulatory system from anthocyanins will be colonic microbiotaderived phenolic acid breakdown products while ellagitannins will be converted to urolithins in the large intestine and are which subsequently absorbed as O-glucuronides.

Regarding fruits and fruit juices (Décordé et al., 2008; Rouanet et al., 2010; Suh et al., 2011), their antioxidant activity is known to reduce diet-induced oxidative stress. Here, we showed that apple and grape and their juices prevent early atherosclerosis, i.e. $10 \%$ foam cell coverage of aorta, in hypercholesterolemic hamsters, with AFSA development being prevented throughout an improvement of the plasma lipid profileand PAC, sparing of SOD and GSHPx activities, and a decrease in the liver TBARS level. A decreased activity of antioxidant enzymes may be a consequence of the sparing effect of dietary antioxidants, reducing the requirement for enzymatic antioxidant function when elevated concentrations of exogenous antioxidants are present in the circulatory system (Breinholt et al., 1999). Elsewhere, spontaneous hepatic lipid peroxidation has been shown to decrease with an increasing level of dietary antioxidants (Leibovitz et al., 1990), and supplementation with apples effectively decreases oxidative stress by decreasing malondialdehyde formation in the body (Pajk et al., 2006). In this study (Décordé et al., 2008), hepatic TBARS concentration decreased in each group. This improvement in the antioxidant status indicated that even a low amount of absorbed phenolics from fruits and juices might decrease lipid oxidation. Thus, our findings suggested that both apples and purple grape, as well as their juices acted by various mechanisms including not only a hypolipemic effect but also, and especially, an antioxidant effect.

Overall, the results clearly showed for the first time that apple and purple grape prevent diet-induced atherosclerosis in hamsters, and that the fruit processing can have a major 
impact on the potential health benefits of fruit in pathological conditions. These findings, therefore, provide encouragement that fruit and fruit juices may have a significant clinical and public health relevance.

Our study on berry juices and teas (Rouanet et al., 2010) demonstrated that when fed to hamsters under atherogenic diet, they are able to facilitate a very strong inhibition of aortic fatty streaks deposition. These effects are physiologically relevant as they were induced by a daily supplement equivalent to $275 \mathrm{ml}$ of beverage consumed on a daily base by a $70 \mathrm{~kg}$ human. There are reports that consumption of fruit juice and green tea both increase the activity of hepatic antioxidant enzymes (Lin et al., 1998; Pajk et al., 2006). This contrasts with the findings of the present study where berry juice and tea consumption lowered hepatic GSHPx and SOD activities, and agree with previous results in hamsters receiving either pure catechin, quercetin or resveratrol (Auger et al., 2005 a) or phenolics from purple grape, apple, purple grape juice and apple juice (Décordé et al., 2008). One explanation for this down regulation is that it is a consequence of dietary antioxidants being able to scavenge oxygen radicals and thus reduce the need for enzymatic endogenous antioxidants. Thus, polyphenol-rich berry juices and green and black tea intake may be of significant relevance to clinical and public health.

In our study on algal polysaccharides, the superoxide anion production induced by the atherogenic diet was prevented by feeding Ulva and processed Ulva which prevented aortic fat deposits. However, the exact explanation of the mechanism underlying the free radical scavenging activity exerted by polysaccharides is still not fully understood. The decrease of aortic fatty steak area by alga suggests that ROS-scavenging effect is a likely mechanism since the above studies have established that polysaccharides not only scavenge ROS but also act as potent antioxidants and inhibit the lipid peroxidation mediated by ROS. It is unlikely that the antioxidant effects of Ulva polysaccharides are attributable to their systemic activity because they are not absorbed. What type of antioxidant is responsible for the observed effects and by what mechanism does it act remains a major problem unresolved. At this stage, we can only propose a hypothesis. The most plausible is that these polysaccharides act only within the lumen by protecting the body against the absorption of radical species and/or by protecting algal antioxidants and nutrients against a possible oxidation before their absorption. Also, the antioxidant effect of some metabolites, produced from polysaccharide fermentation by gut flora, cannot be ruled out. Polysaccharides from other origins such as tea, wolfberry or ginseng have been shown to exert antioxidant activity. The antioxidant mechanism may be due to the supply of hydrogen by the polysaccharide, which combines with radicals and forms a stable radical to terminate the radical chain reaction. The other possibility is that the polysaccharides can combine with the radical ions, which are necessary for radical chain reaction; then the reaction is terminated. However, the exact explanation of the mechanism underlying the free radical scavenging activity exerted by polysaccharides is still not fully understood. The decrease of aortic fatty streak area by chitin-glucan (Berecochea-Lopez et al., 1999) suggests that ROS-scavenging effect is a likely mechanism since the above studies have established that polysaccharides not only scavenge ROS but also act as potent antioxidants and inhibit the lipid peroxidation mediated by ROS. Moreover, improvement of hepatic SOD and GSHPx activities, lowered hepatic TBARS levels, and decreased cardiac superoxide anion production were observed, and aortic cholesterol deposit and fatty streak area development were prevented. These 
results suggest that chitin-glucan acted through an improvement in the antioxidant status indicating that even low amounts of ingested polysaccharides might decrease lipid oxidation. Here also, it is unlikely that the antioxidant effects of chitin-glucan polysaccharides are attributable to their systemic activity because they are not absorbed.

Additionally, a hypolipemic effect of chitin-glucan should not be rejected. To our knowledge, there are no studies reported on the preventive effets of chitin-glucan on atherosclerosis. A comparison could be made with other close nonstarch polysaccharides such as chitosan and dietary fiber components such as $\beta$-glucan. Kamil et al. (2002) demonstrated that among the different viscosity chitosans, $14 \mathrm{cP}$ chitosan was more effective than the higher viscosity chitosans $(57 \mathrm{cP}$ and $360 \mathrm{cP}$ ) in preventing lipid oxidation in the herring flesh model system. Soluble and viscous dietary fibers, such as $\square$-glucans are associated with two major health promoting effects, i.e., the attenuation of postprandial plasma glucose and insulin levels, and the control of cholesterol, that are important in atherosclerosis development. Increased viscosity in the intestine delays absorption of glucose and suppresses the absorption of cholesterol and the reabsorption of bile acids. Since $\beta$-glucan can appear in the digestive tract after feeding hamsters with chitin-glucan, this could be another explanation for the decreased atherosclerotic plaques in our model.

The antioxidant activity of chitosans of different MWs (30,90, and $120 \mathrm{kDa}$ ) has been investigated in salmon (Kim \& Thomas, 2007). In general, all chitosans exhibited antioxidative activities in salmon. The $90 \mathrm{kDa}$ chitosan showed an increased free radicalscavenging activity. Another study (Youn et al., 2001) showed that antioxidative effects of chitosan were increased with larger MW and revealed that the scavenging activities also depended on the MWs of chitosans. However, while the radical scavenging activity of low MW chitosans appears to play a role in their antioxidant activities, this is not the case for the high MW chitosan. In the latter case, its antioxidant activity must be explained by other mechanisms such as metal chelation or lipid binding. This could happen with chitin-glucan and fractions issuing from them. These promising results obtained by dietary supplementation with chitin-glucan from Aspergillus niger in a diet-induced atherosclerosis animal model give rise to its use as a potential dietary therapy. Further investigation is warranted to define the mechanisms by which chitin-glucan provides protection.

However, our recent and innovative studies (Décordé et al., 2009 b; Décordé et al., 2010) on dietary supplementation of a melon juice concentrate rich in SOD (Extramel ${ }^{\circledR}$ ) provides evidence for the first time that such antioxidant protects against diet-induced oxidative stress, atherosclerosis and obesity in hamsters, and no toxicity or evidence of other unwanted pharmacological effects of Extramel $^{\circledR}$ was noted at either levels of supplementation. Our findings suggest for the first time that Extramel ${ }^{\circledR}$ prevents both $\mathrm{NAD}(\mathrm{P}) \mathrm{H}$ oxidase expression and $\mathrm{O}_{2}{ }^{{ }^{-}}$overproduction in the liver from hypercholesterolemic hamster. This could be involved in the prevention of LDL oxidation and further atherosclerosis steps. High Fat-feeding activated and Extramel ${ }^{\circledR}$ reduced $\mathrm{NAD}(\mathrm{P}) \mathrm{H}$ activity (heart and liver) and expression (liver) reinforce the hypothesis of a nutritional modulation of ROS enzymatic producing systems. An additional major novel finding is that Extramel ${ }^{\circledR}$ prevented obesity in HF-fed hamsters by decreasing body weight, abdominal fat, triglyceridemia, insulinemia, insulin resistance, liver lipids, and nonalcoholic steatohepatitis (NASH) and preventing adipokine imbalance, oxidative stress is implicated 
in NASH. All these features due to Extramel ${ }^{\circledR}$ were associated with a huge prevention of aortic fatty streak lipid deposition and NASH. The relative contribution of each parameter is difficult to establish although it is tempting to speculate on a specific role of tissular oxidative stress. Moreover, it may be that these effects are not restricted to SOD activity that could act synergistically or additively with other antioxidant components to prevent atherosclerosis in the hamster model. This indicates that at the low doses used Extramel ${ }^{\circledR}$ is a safe nutraceutical supplement.

Our findings agree with Vouldoukis et al. (2004 a) who did show that feeding mice for 4 weeks with a melon extract exhibiting SOD, catalase and residual GSHPx activities led to an increase in circulating and liver SOD activity. Since Extramel ${ }^{\circledR}$ strongly prevented $\mathrm{O}_{2}{ }^{\circ}$ production and inducted SOD activity, we can assume that it favors the antioxidative balance by decreasing the oxidative stress, thus exhibiting beneficial effects on preventing early atherosclerosis and obesity. Such an increase of liver and blood SOD activity shown by us as well as by Vouldoukis et al. (2004 b) is not observed with other kinds of dietary antioxidants and seems to result from this antioxidant enzyme supplementation: when encapsulated by gliadin, the same melon extract rich in SOD triggers an increase in liver and circulating SOD activity after oral administration to rats not subjected to an oxidative stress. When the melon extract rich in SOD is not protected by gliadin, no more increase in circulating and hepatic SOD activity appeared. Elsewhere, an oral supplementation of pure SOD encapsulated in liposomes promoted the circulating SOD activity; however, if not encapsulated in liposomes, and therefore destroyed at least in part during the digestive process, no longer increased circulating SOD activity can be observed (Regnault et al., 1996). Such an increase in circulating SOD activity also appeared in cats infected with FIV given the extract coated with gliadin (Webb et al., 2008). In the same way, SOD mimics, synthesized molecules reproducing the effect of SOD and resisting to digestive conditions, were used successfully in the treatment of steatohepatitis in murine and they also induced an increase of SOD activity in liver (Laurent et al., 2004). An effect of the coating may be ruled out since an increased endogenous SOD activity appeared regardless of the type of coating used (liposomes, gliadin, palm oil). All these findings showed that increased endogenous SOD activities resulted from melon SOD and not from an active issuing peptide since nothing occurred without coating.

Finally, such an induction of the cell antioxidant status is not observed with other kinds of dietary antioxidants (Auger et al., 2005 a; Riss et al., 2007), suggesting a specific effect of melon SOD. It should be pointed out that circulating erythrocytes, which do not contain nuclei, are not able to induce new synthesis of SOD once they enter the bloodstream. Since their circulating life span is about 120 days, thus, during the 12-week course of the experiment about $70 \%$ of the erythrocytes would not have been still replaced by maturing reticulocytes from the bone marrow. This $11 \%$ increase therefore represents the SOD inducted by supplementation. As expected in liver, a more important induction appeared, as all cells in this tissue have nuclei and ongoing synthesis of new protein. However, as pointed out by McCord and Edeas (2005) overexpression of SOD could be lethal and doseresponse curves have been established after isolated hearts were subjected to ischemiareperfusion injury and protected by exogenous SOD (Omar et al., 1990). SOD was very protective up to a point, beyond which protection was lost and injury was even exacerbated, 
with increased lipid peroxidation. This was corroborated by Levy et al. (2002) who found that high overexpression of SOD increased ischemia-reperfusion injury to the brain. Even at the higher dose of supplementation used by us, Extramel ${ }^{\circledR}$ did not lead to such upper limit dose dependent ending events, strengthening its safety as nutraceutical supplement. Even though involved mechanisms remain unclear, it is known that SOD can be absorbed despite its high MW ( $35 \mathrm{kDa})$. This was shown in the liver of rats after intravenous administration of SOD conjugated with colloidal gold (Dini et al., 1996) and more recently in HT-29 cells using liposomal SOD and the SOD mimic tempamine (Jubeh et al., 2005).

To summarize, Extramel ${ }^{\circledR}$ prevented obesity in High Fat-fed hamsters by decreasing body abdominal and liver fat and by preventing adipokine imbalance. Furthermore, oxidative stress was reduced (decreased levels of lipids and protein oxidation products), and the main sources of ROS production (NADPH and mitochondria) were modified as NADPHdependent $\mathrm{O}_{2}{ }^{\circ}$ - production and mitochondrial maximal activity of cytochrome oxidase decreased with Extramel ${ }^{\circledR}$. These promising results give rise to the use of Extramel ${ }^{\circledR}$ as potential dietary therapy and to further clinical studies. Investigation is warranted to define the mechanisms by which Extramel ${ }^{\circledR}$ protects.

It is generally assumed that obesity is a prooxidant state related in part to insulin resistance. In addition, autoxidation of glucose and nonenzymatic glycation of proteins may generate superoxide (Baynes, 1991), a radical species implicated in vascular cell-mediated LDL oxidation. Hyperglycemia also induces the enzymatic production of superoxide through activation of $\mathrm{NAD}(\mathrm{P}) \mathrm{H}$ oxidase in vascular cells (Inoguchi et al., 2000). Elsewhere, insulin itself promotes hydrogen peroxide generation in fat cells (Krieger-Brauer et al., 1992) prompting speculation that oxidative stress is a principal mechanism of insulin resistance with chronic hyperinsulinemia. This hypothesis is further supported by Fortuno et al. (2006) suggesting that hyperinsulinemia may contribute to oxidative stress in metabolic syndrome patients through activation of $\mathrm{NAD}(\mathrm{P}) \mathrm{H}$ oxidase. On the other hand, it has also been suggested that lipid disorders could enhance ROS formation. The observed overproduction of superoxide anion in neutrophils from hyperlipidemic guinea pig could be linked to an induction of $\mathrm{NAD}(\mathrm{P}) \mathrm{H}$ oxidase subunit in particular gp91phox (Maeda et al., 2005). It has been reported in humans that systemic oxidative stress is strongly associated with visceral fat accumulation and metabolic syndrome (Fujita et al., 2006). Our observation of a HFDinduced obesity associated with insulin resistance and lipid disorders enhancing NAD $(\mathrm{P}) \mathrm{H}$ oxidase expression $(+270 \%$, Table 13$)$ in cardiac tissue extends these observations, suggesting that insulin resistance and dyslipidemia conspire in oxidative stress. NAD $(\mathrm{P}) \mathrm{H}$ oxidase overexpression and activity could be also related to adipokine imbalance. In adiponectine -/- mice an overexpression of $\mathrm{NAD}(\mathrm{P}) \mathrm{H}$ oxidase subnunits has been observed in heart (Tao et al., 2007) and kidneys (Ohashi et al., 2007) strongly showing that adiponectine could downregulate superoxide anion production. Elsewhere, it has been recently demonstrated that leptin increases $\mathrm{NAD}(\mathrm{P}) \mathrm{H}$ oxidase protein expression and activity in isolated murine cardiomyocytes and this effect is attenuated by endothelin (ET-1) receptor antagonists (Dong et al., 2006). The observation that grape seed tannin extract (GSE) both improves adiponectin and leptin levels (Table 12) and decreases NAD(P)H oxidase expression and activity (Table 13) strongly suggests a potential link between these events. Whether endothelin plays a pathogenic role in obesity is not clear, but in experimental 
obesity, there is an increase in gene and protein expression of endothelin in the cardiovascular system, including vasculature and kidney (Barton et al., 2000). Because leptin stimulates endothelin-1 production in cardiomyocytes ( $\mathrm{Xu}$ et al., 2004) as well as in endothelial cells (Quehenberger et al., 2002), these results suggest that leptin may stimulate ROS formation through endothelin and $\operatorname{NAD}(\mathrm{P}) \mathrm{H}$ oxidase dependent pathway and that phenolics present in GSE are efficient in reducing these effects. As demonstrated by Corder et al. (2006), phenolic compounds, principally procyanidins, are able to reduce the production of endothelin-1 by endothelial cells. Inhibition of endothelin-1 overexpression is, therefore, a further potential mechanism for the observed protective effects of GSE consumption. From this study, we can assume that $\mathrm{NAD}(\mathrm{P}) \mathrm{H}$ oxidase is upregulated by HFD due to adipokine imbalance and viceral fat accumulation (Table 12), and possibly ET-1 overexpression. GSE could prevent all these events. Interestingly, HFD increased liver antioxidant enzymes mainly SOD and GSHPx activity that could in part counteract the increase in $\mathrm{O}_{2}{ }^{\circ}$ - production; this could be due to an oxidative system-induced regulation (Maggy-Capeyron et al., 2002). In this context, GSE consumption lowered hepatic SOD and GSHPx activities (not shown here). One explanation for this downregulation is that it is a consequence of the sparing effect of dietary antioxidants being able to scavenge oxygen radicals, and thus reduce the requirement for enzymatic endogenous antioxidant (Breinholt et al., 1999; Auger et al., 2005 a; Décordé et al., 2008) Since GSE totally prevent $\mathrm{O}_{2}{ }^{\circ}$ production (Table 13) but only partly decreased SOD and GSHPx activities, we can assume that GSE favours the antioxidative balance. Thus, grape seed tannins extract has beneficial effects on preventing diet-induced obesity by improving oxidative stress markers. All of these results suggest that grape seed tannins acted by mechanisms operating at least in partinside an antioxidant effect and the possibility that adiponectin might modulate oxidative stress, leading to antiobesity effects. Thus, we provided insights into one mechanism, increased oxidative stress, that probably contributes to the pathological after-effects of obesity and that may have important public health implications, being a target for interventions to decrease the pathology. Therefore, the potential for antioxidant therapy to decrease obesity risks needs to be explored.

\section{Conclusion}

However, it should be kept in mind that the association between inflammation and oxidative stress (OS) is underlaid by molecular mechanisms leading to amplification loops between pro-inflammatory mediators and oxidant production. Thus the presence of oxidative stress will stimulate some transcription factors such as AP-1, NF- $\kappa \mathrm{B}$, PPARs or the hypoxemia induced factor, either directly by reactive forms of oxygen or indirectly through peroxidation products. Once activated, these factors control the expression of proinflammatory molecules such as iNOS, adhesion molecules and cytokines, which will in turn stimulate the $\mathrm{NAD}(\mathrm{P}) \mathrm{H}$ oxidase, originating other reactive forms. Although the initial production of $\mathrm{O}_{2}{ }^{\circ}$ (the "spark" oxidative) may come from other sources such as the system xanthine/xanthine oxidase or mitochondrial dysfunction, the system $\mathrm{NAD}(\mathrm{P}) \mathrm{H}$ oxidase/NOX appears to play a key role in the amplification OS/inflammation. Our general hypothesis postulates that nutrition can modulate either positively or negatively amplification loops OS/inflammation. The association between OS and inflammation is 
observed during chronic diseases and may be considered as an aggravating factor. Thus, such an association may be involved in the conversion between insulin resistance and diabetes or cardiovascular complications of obesity.

Then, dietary antioxidants can play a key role in the regulation of the oxidant status and it seems essential to develop and utilise natural antioxidants so that they can retard the progress of many chronic diseases. The consumption of antioxidant rich fruits and vegetables that generally supplies minerals, vitamins, fibers, phytochemicals such as phenolics but also provides antioxidant enzymes is therefore advised.

\section{References}

Adams, M. R., Golden, D. L., Chen, H., Register, T. C., Gugger, E. T. A diet rich in green and yellow vegetables inhibits atherosclerosis in mice. J. Nutr. 2006, 136, 1886-9.

Al-Awwadi, N. A., Araiz, C., Bornet, A., Delbosc, S., Cristol, J.P., Linck, N., Azay, J., Teissedre, P.L., Cros, G. Extracts enriched in different polyphenolic families normalize increased cardiac NADPH oxidase expression while having differential effects on insulin resistance, hypertension, and cardiac hypertrophy in highfructose-fed rats. J. Agric. Food Chem. 2005, 53, 151-7.

Aruoma, O.I. Nutrition and health aspects of free radicals and antioxidants. Food Chem. Toxicol. 1994, 32, 671-83. Auger, C., Caporiccio, B., Landrault, N., Teissèdre, P. L., Laurent, C., Cros, G., Besançon, P., Rouanet, J. M. Red wine phenolic compounds reduce plasma lipids and apolipoprotein $B$, and prevent early aortic atherosclerosis in hypercholesterolemic Golden Syrian hamsters (Mesocricetus auratus). J. Nutr. 2002, 132, 1207-13.

Auger, C., Gérain, P., Laurent-Bichon, F., Portet, K., Bornet, A., Caporiccio, B., Cros, G., Teissèdre, P.L., Rouanet, J.M. Phenolics from commercialized grape extracts prevent early atherosclerotic lesions in hamsters by mechanisms other than antioxidant effect. J. Agric. Food Chem. 2004, 52, 5297-302.

Auger, C., Teissèdre, P.L., Gérain, P., Lequeux, N., Bornet, A., Serisier, S., Besançon, P., Caporiccio, B., Cristol, J.P., Rouanet, J.M. Dietary wine phenolics catechin, quercetin and resveratrol efficiently protect hypercholesterolemic hamsters against aortic fatty streak accumulation. J. Agric. Food Chem. 2005 a, 53, 2015-21.

Auger, C., Rouanet, J.M., Vanderlinde, R., Bornet, A., Décordé, K., Lequeux, N., Cristol, J.P., Teissèdre, P.L. Polyphenols-enriched chardonnay white wine and sparkling pinot noir red wine identically prevent early atherosclerosis in hamsters. J. Agric. Food Chem. 2005 b, 53, 9823-9.

Aviram, M., Dornfeld, L., Rosenblat, M., Volkova, N., Kaplan, M., Coleman, R., et al.. Pomegranate juice consumption reduces oxidative stress, atherogenic modifications to LDL, and platelet aggregation: Studies in humans and in atherosclerotic apolipoprotein E-deficient mice. Am. J. Clin. Nutr. 2000, 71, 1062-76.

Barton, M., Carmona, R., Morawietz, H., d'Uscio, L.V., et al. Obesity is associated with tissue-specific activation of renal angiotensin-converting enzyme in vivo: Evidence for a regulatory role of endothelin. Hypertension 2000, 35, 329-36.

Barwicz, J., Gruda, I., Tancrede, P. A kinetic study of the oxidation effects of amphotericin B on human low-density lipoproteins. FEBS Letters 2000, 465, 83-6. 
Baynes, J. W. Role of oxidative stress in the development of complications in diabetes. Diabetes 1991, 40, 405-12.

Berecochea-Lopez, A., Décordé, K., Ventura, E., Godard, M., Bornet, A., Teissèdre, P.L., Cristol, J.P., Rouanet, J.M. Fungal chitin-glucan from Aspergillus niger efficiently reduces aortic fatty streak accumulation in the high-fat fed hamster, an animal model of nutritionally induced atherosclerosis, J. Agric. Food Chem. 2009, 57, 1093-8.

Bhat, V.B., Madyastha, K.M. C-phycocyanin: a potent peroxyl radical scavenger in vivo and in vitro. Biochem. Biophys. Res. Commun. 2000, 275, 20-5.

Bhat, V.B., Madyastha, KM. Scavenging of peroxynitrite by phycocyanin and phycocyanobilin from Spirulina platensis: protection against oxidative damage to DNA. Biochem. Biophys. Res. Commun. 2001, 286, 262-6.

Braddon, F.E., Rodgers, B., Wadsworth, M.E. Onset of obesity in a 36 year birth cohort study. Br. Med. J. 1986, 293, 299-303.

Breinholt, V., Lauridsen, S.T., Dragsted, L.O. Differential effects of dietary flavonoids on drug metabolizing and antioxidant enzymes in female rat. Xenobiotica 1999, 29, 1227-40.

Carmiel-Haggai, M., Cederbaum, A.I., Nieto, N. A high-fat diet leads to the progression of non-alcoholic fatty liver disease in obese rats. FASEB J. 2005, 19, 136-8.

Cases, J., Vacchina, V., Napolitano, A., Caporiccio, B., Besançon, P., Lobinski, R., Rouanet, J.M. Selenium from selenium-rich Spirulina is less bioavailable than selenium from sodium selenite and selenomethionine in selenium-deficient rats. J. Nutr. 2001, 131, 2343-50.

Cases, J., Wysocka, I.A., Caporiccio, B., Jouy, N., Szpunar, J., Rouanet, J.M. Assessment of selenium bioavailability from high-selenium Spirulina subfractions in seleniumdeficient rats. J. Agric. Food Chem. 2002, 50, 3867-73.

Chen, C., Zhang, P., Hou, X., Chai, Z. Subcellular distribution of selenium and Se-containing proteins in human liver. Biochim. Biophys. Acta 1999, 1427, 205-15.

Chen, F., Zhang, Y.M., Guo, S.Y. Growth and phycocyanin formation of Spirulina platensis in photoheterotrophic culture. Biotechnol. Lett. 1996, 18, 603-8.

Chen, H., Zhang, M., Xie, B. Components and antioxidant activity of polysaccharide conjugate from green tea. Food Chem. 2005, 90, 17-21.

Corder, R., Mullen, W., Khan, N. Q., Marks, S. C., et al. Red wine procyanidins and vascular healt. Nature 2006, 444, 566-70.

Dauchet, L., Amouyel, P., Hercberg, S., Dallongeville, J. Fruit and vegetable consumption and risk of coronary heart disease: a meta-analysis of cohort studies. J. Nutr. 2006, 136, 2588-93.

Décordé, K., Teissèdre, P.L., Auger, C., Cristol, J.P., Rouanet, J.M. Phenolics from purple grape, apple, purple grapejuice and apple juice prevent early atherosclerosis induced by an atherogenic diet in hamsters. Mol. Nutr. Food Res. 2008, 52, 400-7.

Décordé, K., Teissèdre, P.L., Sutra, T., Ventura, E., Cristol, J.P., Rouanet, J.M. Chardonnay grape seed procyanidin extract supplementation prevents high-fat diet-induced obesity in hamsters by improving adipokine imbalance and oxidative stress markers. Mol. Nutr. Food Res. 2009 a, 53, 659-66.

Décordé, K., Agne, A., Lacan, D., Ramos, J., Fouret, G., Ventura, E., Feillet-Coudray, C., Cristol, J.P., Rouanet, J.M. Preventive effect of a melon extract rich in superoxide 
scavenging activity on abdominal and liver fat and adipokine imbalance in highfat-fed hamsters. J. Agric. Food Chem. 2009 b, 57, 6461-7.

Décordé, K., Ventura, E., Lacan, D., Ramos, J., Cristol, J.P., Rouanet, J.M. A SOD rich melon extract Extramel ${ }^{\circledR}$ prevents aortic lipids and liver steatosis in diet-induced model of atherosclerosis. Nutr. Metabol. Cardiovasc. Dis. 2010, 20, 301-7.

Dini, L., Falasca, L., Rossi, L., Rotilio, G. In vivo uptake of $\mathrm{Cu}, \mathrm{Zn}$ superoxide dismutase. Morphological evidence for preferential endocytosis and accumulation by sinusoidal liver cells. Cell Mol. Biol. 1996, 42, 269-77.

Dong, F., Zhang, X., Renx, J. Leptin regulates cardiomyocyte contractile function through endothelin-1 receptor-NADPHoxidase pathway. Hypertension 2006, 47, 222-9.

Duan, X. J., Zhang, W. W., Li, X. M., Wang, B. G. Evaluation of antioxidant property of extract and fractions obtained from a red alga, Polysiphonia urceolata. Food Chem. 2006, 95, 37-43.

Esposito, K., Pontillo, A., Di Palo, C., Giugliano, G. et al. Effect of weight loss and lifestyle changes on vascular inflammatory markers in obese women: a randomized trial. JAMA 2003, 282, 1799-1804.

Fan, L., Zhang, S., Yu, L., Ma, L. Evaluation of antioxidant property and quality of breads containing Auricularia auricula polysaccharide flour. Food Chem. 2007, 101, 1158-63.

Fecondo, J.V., Augusteyn, R.C. Superoxide dismutase, catalase and glutathione peroxidase in the human cataractous lens. Exp. Eye Res. 1983, 36, 15-23.

Fortuno, A., San Jose, G., Moreno, M. U., Beloqui, O., et al. Phagocytic NADPH oxidase overactivity underlies oxidative stress in metabolic syndrome. Diabetes 2006, 55, 209-15.

Frei, B. Reactive oxygen species and antioxidant vitamins: Mechanisms of action. Am. J. Med. 1994, 97, 5S-13S. 22S-28S.

Fujita, K., Nishizawa, H., Funahashi, T., Shimomura, I., Shimabukuro, M. Systemic oxidative stress is associated with visceral fat accumulation and the metabolic syndrome. Circ. J. 2006, 70, 1437-42.

Furukawa, S., Fujita, T., Shimabukuro, M., Iwaki, M., et al. Increased oxidative stress in obesity and its impact on metabolic syndrome. J. Clin. Invest. 2004, 114, 1752-61.

Gallistl, S., Sudi, K., Mangge, H., Erwa, W., Borkenstein, M. Insulin is an independant correlate of plasma homocysteinelevels in obese children and adolescents. Diabetes Care 2000, 23, 1348-52.

Georgescu, A., Alexandru, M., Constantinescu, E., Popo, B. Effect of gap junction uncoupler heptanol on resistance arteries reactivity in experimental model of diabetes, hyperlipemia and hyperlipemia-diabetes. Vasc. Pharmacol. 2006, 44, 513-8.

Godard, M., Décordé, K., Ventura, E., Soteras, G., Baccou, J.C., Cristol, J.C., Rouanet, J.M. Polysaccharides from the green alga Ulva rigida improve the antioxidant status and prevent fatty streak lesions in the high cholesterol fed hamster, an animal model of nutritionally-induced atherosclerosis. Food Chem. 2009, 115, 176-80.

Hansen, P.A., Han, D.H., Nolte, L.A., Chen, M., Holloszy, J.O. DHEA protects against visceral obesity and muscle insulin resistance in rats fed a high-fat diet. Am. J. Physiol. 1997, 273, 1704-8.

Haslam, D.W., James, W.P.T. Obesity. Lancet 2005, 366, 1197-1209. 
Huang, Z., Guo, B.J., Wong, R.N.S., Jiang, Y. Characterization and antioxidant activity of selenium-containing phycocyanin isolated from Spirulina platensis. Food Chem. 2007, 100, 1137-43.

Imlay, J.A., Linn, S. DNA damage and oxygen radical toxicity. Science 1998, 240, 1302-9.

Inoguchi, T., Li, P., Umeda, F., Yu, H. Y., et al. High glucose level and free fatty acid stimulate reactive oxygen species production through protein kinase C-dependent activation of NAD(P)H oxidase in cultured vascular cells. Diabetes 2000, 49, 1939-45.

Ip, C., Lisk, D.J., Ganther, H.E. Chemoprevention with triphenylselenonium chloride in selenium-deficient rats. Anticancer Res. 2000, 20, 4179-82.

Iwata, K., Inayama, T., Kato, T. Effects of Spirulina platensis on plasma lipoprotein lipase activity in fructose-induced hyperlipidemic rats. J. Nutr. Sci. Vitaminol. 1990, 36, 165-71.

Jiang, Y. H., Jiang, X. L., Wang, P., Hu, X. K. In vitro antioxidant activities of water-soluble polysaccharides extracted from Isaria farinosa B05. J. Food Biochem. 2005, 29, 323-35.

Jubeh, T.T., Antier, S., Haupt, S., Barenholz, Y., Rubinstein, A. Local prevention of oxidative stress in the intestinal epithelium of the rat by adhesive liposomes of superoxide dismutase and tempamine. Mol. Pharm. 2005, 2, 2-11.

Kamil, Y.V.A.J., Jeon, Y.J., Shahidi, F. Antioxidative activity of chitosans of different viscosity in cooked comminuted flesh of herring (Clupea harengus). Food Chem. 2002, 79, 69-77.

Katagiri, K., Arakawa, S., Kurahashi, R., Hatano, Y. Impaired contact hypersensitivity in diet-induced obese mice. J. Dermatol. Sci. 2007, 46, 117-26.

Keaney, J.F., Larson, M.G., Vasan, R.S., Wilson, P.W.F. et al. Obesity and systemic oxidative stress : clinical correlates of oxidative stress in the Framingham Study. Arterioscler. Thromb. Vasc. Biol. 2003, 23, 434-9.

Kick, J., Hauser, B., Bracht, H., Albicini, M., Öter, S., Simon, F., et al. Effects of a cantaloupe melon extract/wheat gliadin biopolymer during aortic cross-clamping. Int. Care Med. 2007, 33, 694-702.

Kim, K.W., Thomas, R.L. Antioxidative activity of chitosans with varying molecular weights. Food Chem. 2007, 101, 308-3.

Klaus, S., Pultz, S., Thone-Reineke, C., Wolfram, S. Epigallocatechin gallate attenuates dietinduced obesity in mice by decreasing energy absorption and increasing fat oxidation. Int. J. Obesity 2005, 29, 615-23.

Kowala, M. C., Nunnari, J. J., Durham, S. K., Nicolosi, R. J. Doxazosin and cholestyramine similarly decrease fatty streak formation in the aortic arch of hyperlipidemic hamsters. Atherosclerosis 1991, 91, 35-49.

Krieger-Brauer, H. I., Kather, H. Human fat cells possess a plasma membrane-bound $\mathrm{H}_{2} \mathrm{O}_{2}-$ generating system that is activated by insulin via a mechanism bypassing the receptor kinase, J. Clin. Invest. 1992, 89, 1006-13.

Lacan, D., Baccou, J. C. High levels of antioxidant enzymes correlate with delayed senescence in nonnetted muskmelon fruits. Planta 1998, 204, 377-82.

Laurent, L., Nicco, C., Tran Van Nhieu, J., Borderie, D., Chéreau, C., Conti, F., et al. Pivotal role of superoxide anion and benefical effect of antioxidant molecules in murine steatohepatitis. Hepatology 2004, 39, 1277-85. 
Leibovitz, B., Hu, M.L., Tappel, A.L. Dietary supplements of vitamin E, $\square$-carotene, coenzyme Q10 and selenium protect tissues against lipid peroxidation in rat tissue slices. J. Nutr. 1990, 120, 97-104.

Leung, N., Naples, N., Uffelman, K., Szeto, L. et al. Rosglitazone improves intestinal lipoprotein overproduction in tha fat-fed Syrian Golden hamster, an animal model of nutritionally-induced insulin resistance. Atherosclerosis 2004, 174, 235-41.

Levy, R., Glozman, S., Milman, D., Seruty, C., Hagay, Z., Yavin, E., et al. Ischemic reperfusion brain injury in fetal transgenic mice with elevated levels of copperezinc superoxide dismutase. J. Perinat. Med. 2002, 30, 158-65.

Lin, Y.L., Cheng, C.Y., Lin, Y.P., Lau, Y.W., Juan, I.M., Lin, J.K. Hypolipidemic effect of green tea leaves through induction of antioxidant andPhase II enzymes including superoxide dismutase, catalase, and glutathione $\mathrm{S}$ transferase in rats. J. Agric. Food Chem. 1998, 46, 1893-9.

Luft, R., Landau, B. R. Mitochondrial medicine. J. Intern. Med. 1995, 238, 405-21.

Maeda, K., Yasunari, K., Sato, E. F., Inoue, M. Enhanced oxidative stress in neutrophils from hyperlipidemic guinea pig. Atherosclerosis 2005, 181, 87-99.

Maggy-Capeyron, M.F., Cases, J., Badia, E., Cristol, J.P., et al. A diet high in cholesterol and deficient in vitamin $\mathrm{E}$ induces lipid peroxidation but does not enhance antioxidant enzyme expression in rat liver. J. Nutr. Biochem. 2002, 13, 293-301.

McCord, J.M., Edeas, M.A. SOD, oxidative stress and human pathologies: a brief history and a future vision. Biomed. Pharmacother. 2005, 59, 139-42.

Miller, S., Walker, S.W., Arthur, J.R., Nicol, F., Pickard, K., Lewin, M.H., Howie, A.F., Beckett, G.J. Selenite protects human endothelial cells from oxidative damage and induces thioredoxin reductase. Clin Sci. 2001, 100, 543-50.

Mokdad, A.H., Ford, E.S., Bowman, B.A., Dietz, W.H. et al. Prevalence of obesity, diabetes, and obesity-related health risk factors, 2001. JAMA 2003, 289, 76-9.

Morinobu,T., Murata, T., Takaya, R., Tamai, H. Nutritional status of $\beta$-carotene, $\alpha$-tocopherol and retinol in obese children. Int. J. Vitam. Nutr. Res. 2002, 72, 119-23.

Murase, T., Nagasawa, A., Suzuki, J., Hase, T., Tokimitsu, I. Beneficial effects of tea catechins on diet-induced obesity: stimulation of lipid catabolism in the liver. Int. J. Obesity 2002, 26, 1459-64.

Muth, C.M., Glenz, Y., Klaus, M., Radermacher, P., Speit, G., Leverve, X., et al. Influence of an orally effective SOD onhyperbaric oxygen-related cell damage. Free Radic. Res. $2004,38,927-32$.

Nagao, T., Hase, T., Tokimitsu, I.A green tea extract high in catechins reduces body fat and cardiovascular risks in humans. Obesity 2007, 15, 1473-83.

Nagaoka, S., Shimizu, K., Kaneko, H., Shibayama, F., Morikawa, K., Kanamaru, Y., Otsuka, A., Hirahashi, T., Kato, T. A novel protein C-Phycocyanin plays a crucial role in the hypocholesterolemic action of Spirulina platensis concentrate in rats. J. Nutr. 2005, 135, 2425-30.

Nakagawa, K., Kishida, H., Arai, N., Nishiyama, T., Mae, T. Licorice flavonoids suppress abdominal fat accumulation and increase in blood glucose level in obese diabetic KK-Ay mice. Biol. Pharm. Bull. 2004, 27, 1775-8.

Nakamura, T., Tokunaga, K., Shimomura, I., Nishida. M. et al. Contribution of visceral fat accumulation to the development of coronary artery disease in non-obese men, Atherosclerosis 1994, 107, 239-46. 
Nakaya, N., Homma, Y., Goto, Y. Cholesterol lowering effect of spirulina. Nutr. Rep. Int. 1988, 37, 1329-37.

Nelson, S.K., Bose, S.K., Grunwald, G.K., Myhill, P., McCord, J.M. The induction of human superoxide dismutase and catalase in vivo: a fundamentally new approach to antioxidant therapy. Free Radic. Biol. Med. 2006, 40, 341-7.

Neuhouser, M.L., Rock, C.L., Eldridge, A.L., Kristal, A.R., Patterson, R.E., et al. Serum concentrations of retinol, $\alpha$-tocopherol and the carotenoids are influenced by diet, race and obesity in a sample of healthy adolscents. J. Nutr. 2001, 131, 2184-91.

Ng, T. B., He, J. S., Niu, S. M., Zhao, L., Pi, Z. F., Shao, W., et al.. A gallic acid derivative and polysaccharides with antioxidative activity from rose (Rosa rugosa) flowers. J. Pharm.Pharmacol. 2004, 56, 537-45.

Nicolle, C., Cardinaut, M., Aprikian, O., Busserolle, J., Grolier, P., Rock, E., Demigné, C., Mazur, A., Sclabert, A., Amouroux, P., Rémézy, C. Effect of a carrot intake on cholesterol metabolism and on anti-oxidant status in cholesterol-fed rat. Eur. J. Nutr. 2003, 42, 254-61.

Nicolle, C., Cardinaut, M., Gueux, E., Jaffrelo, L., Rock, E., Mazur, A., Amouroux, P., Rémézy, C. Health effect of vegetablebased diet : lettuce consumption improves cholesterol metabolism and antioxidant status in the rat. Clin. Nutr. 2004, 23, 605-14.

Nistor, A., Bulla, A., Filip, D.A., Radu, A. The hyperlipidemic hamster as a model of experimental atherosclerosis. Atherosclerosis 1987, 68, 159-73.

Ohashi, K., Iwatani, H., Kihara, S., Nakagawa, Y., et al. Exacerbation of albuminuria and renal fibrosis in subtotal renal ablation model of adiponectin-knockout mice. Arterioscler. Thromb. Vasc. Biol. 2007, 27, 1910-7.

Okamoto, Y., Kihara, S., Ouchi, N., Nishida, M., et al. Adiponectin reduces atherosclerosis in apolipoprotein E-deficient mice. Circulation 2002, 106, 2767-70.

Olson, O.E. , Palmer, S. Selenium in food consumed by South Dakotans. Proc. S. D. Acad Sci. $1978,57,113-21$.

Olusi, S.O. Obesity is an independant risk factor for plasma lipid peroxidation and depletion of erythrocyte cytoprotectic enzymes in humans. Int. J. Obes. Relat. Metab. Disord. 2002, 26, 1159-64.

Omar, B.A., Gad, N.M., Jordan, M.C., Striplin, S.P., Russell, W.J., Downey, J.M., et al. Cardioprotection by $\mathrm{Cu}, \mathrm{Zn}$-superoxide dismutase is lost at high doses in the reoxygenated heart. Free Radic. Biol. Med. 1990,9, 465-71.

Ozata, M., Mergen, M., Oktenli, C., Aydin, A., et al. Increased oxidative stress and hypozincemia in male obesity. Clin. Biochem. 2002, 35, 627-31.

Pajk, T., Rezar, V., Levart, A., Salobir, J. Efficiency of apples, strawberries, and tomatoes for reduction of oxidative stress in pigs as a model for humans. Nutrition 2006, 22, 376384.

Pinero Estrada, J.E., Bermejo Bescos, P., Villar del Fresno, A.M. Antioxidant activity of different fractions of Spirulina platensis protean extract. Il Farmaco 2001, 56, 497 500 .

Prieur, C., Rigaud, J., Cheynier, V., Moutounet, M. Oligomeric and polymeric procyanidins from grape seeds. Phytochemistry 1994, 36, 781-4.

Qi, H., Zhang, Q., Zhao, T., Hu, R., Zhangc, K., Li, Z. In vitro antioxidant activity of acetylated and benzoylated derivatives of polysaccharide extracted from Ulva pertusa (Chlorophyta). Bioorg. Med. Chem. Lett. 2006, 16, 2441-5. 
Quehenberger, P., Exner, M., Sunder-Plassmann, R., Ruzicka, K., et al. Leptin induces endothelin-1 in endothelial cells in vitro. Circ. Res. 2002, 90, 711-8.

Reddy, C.M., Bhat, V.B., Kiranmai, G., Reddy, M.N., Reddanna, P., Madyastha, K.M. Selective inhibition of cyclooxygenase-2 by C-phycocyanin, a biliprotein from Spirulina platensis. Biochem. Biophys. Res. Commun. 2000, 277, 599-603.

Regnault, C., Soursac, M., Roch-Arveiller, M., Postaire, E., Hazebroucq, G. Pharmacokinetics of superoxide dismutase in rats after oral administration. Biopharm. Drug Dispos. 1996, 17, 165-74.

Rice-Evans, C., Leake, D., Bruckdorfer, K. R., \& Diplock, A. T. Practical approaches to low density lipoprotein oxidation: Whys, wherefores and pitfalls. Free Radic. Res. 1996, 25, 285-311.

Riss, J., Décordé. K., Sutra, T., Delage, M., Baccou, J.C., Jouy, N., Brune, J.P., Oréal, H., Cristol, J.P., Rouanet, J.M. The phycobiliprotein C-Phycocyanin from Spirulina platensis is powerfully responsible for reducing oxidative stress and NADPH oxidase expression induced by an atherogenic diet in hamsters. J. Agric. Food Chem. 2007, 55, 7962-7.

Rosenblat, M., Hayek, T., Aviram, M. Anti-oxidative effects of pomegranate juice (PJ) consumption by diabetic patients on serum and onmacrophages. Atherosclerosis 2006, 187, 363-71.

Rouanet, J.M., Décordé, K., Del Rio, D., Auger, C., Borges, G., Cristol, J.P., Lean, M.E.J., Crozier, A. Berry juices, teas, antioxidants and the prevention of atherosclerosis in hamsters. Food Chem. 2010, 118, 266-71.

Saito, M., Ueno, M., Ogino, S., Kubo, K. et al. High dose of Garcinia cambogia is effective in suppressing fat accumulation in developing male Zucker obese rats, but highly toxic to the testis. Food. Chem. Toxicol. 2005, 43, 411-9.

Salonen, J.T., Alfthan, G., Huttunen, J.K., Puska, P. Association between selenium status and the risk of cancer. Am. J. Epidemiol. 1984, 120, 342-9.

Sanchez-Margalet, V., Valle, M., Ruz, FJ., Gascon, F., Mateo, J., et al. Elevated plasma total homocysteine levels in hyperinsulinemic obese subjects. J. Nutr. Biochem. 2002, 13, 75-9.

Schrauzer, G.N., White, D.A., Schneider, C.J. Cancer mortality correlation studies. III. Statistical associations with dietary selenium intakes. Bioinorg. Chem. 1977, 7, 23-34.

Shamberger, R.J., Willis, C.E., McCormack, L.J. Selenium and heart disease. III. Blood selenium and heart mortality in 19 states. In: Trace Substances in Environmental Health (Hemphill, D. D., ed.), 1978 ; vol. 12, pp. 59-63. University of Missouri Press, Columbia, MO.

Simon, E., Macarulla, M.T., Churruca, I., Fernandez-Quintela, A. et al. Trans-10, cis-12 conjugated linoleic acid prevents adiposity but not insulin resistance induced by an atherogenic diet in hamsters. J. Nutr. Biochem. 2006, 17, 126-31.

Sorescu, D., Griendling, K.K. Reactive oxygen species, mitochondria, and NAD $(\mathrm{P}) \mathrm{H}$ oxidases in the development and progression of heart failure. Congest. Heart Fail. $2002,8,132-40$.

Stocker, R., McDonagh, A.F., Glazer, A.N., Ames, B.N. Antioxidant activities of bile pigments: biliverdin and bilirubin. Methods Enzymol. 1990, 186, 301-9. 
Stoewsand, G.S., Anderson, J.L., Munson, L., Lisk, D.J. Effect of diatery Brussels sprouts with increased selenium content on mammary carcinogenesis in the rat. Cancer Lett. $1989,45,43-8$.

Sugiyama, H., Akazome, Y., Shoji, T., Yaamaguchi, A. et al. Oligomeric procyanidins in apple polyphenol are main active components for inhibition of pancreatic lipase and triglyceride absorption. J. Agric. Food Chem. 2007, 55, 4604-9.

Suh, J.H., Romain, C., Gonzalez-Barrio, R., Cristol, J.P., Teissèdre, P.L., Crozier, A., Rouanet, J.M. Raspberry juice consumption, oxidative stress and reduction of atherosclerosis risk factors in hypercholesterolemic golden Syrian hamsters. Food Funct. 2011, 2, 400-5.

Sutra, T., Décordé, K., Riss, J., Dallas, C., Cristol, J.P., Rouanet, J.M. A commercial extract of fruits and vegetables, oxxynea, acts as a powerful antiatherosclerotic supplement in an animal model by reducing cholesterolemia, oxidative stress, and NADPH oxidase expression. J. Agric. Food Chem. 2007, 55, 4258-63.

Tao, L., Gao, E., Jiao, X., Yuan, Y., et al. Adiponectin cardioprotection after myocardial ischemia/reperfusion involves the reduction of oxidative/nitrative stress. Circulation 2007, 115, 1408-16.

Tarp, U., Overvad, K., Hansen, J.C, Thorling, E.B. Low selenium level in severe rheumatoid arthritis. Scand. J. Rheumatol. 1985, 14, 97-101.

Vadillo, M., Ardevol, A., Fernàndez-Larrea, J., Pujadas, G. et al. Moderate red-wine consumption partially prevents body weight gain in rats fed a hyperlipidic diet. $J$. Nutr. Biochem. 2006, 17, 139-42.

Van Vleet, J.F. Current knowledge of selenium-vitamin E deficiency in domestic animals. J. Am. Vet. Med. Assoc. 1980, 176, 321-32.

Vinson, J. A., Teufel, K., Wu, N. Red wine, dealcoholized red wine, and espacially grape juice, inhibit atherosclerosis in a hamster model. Atherosclerosis 2001, 156, 67-72.

Vouldoukis, I., Conti, M., Krauss, P., Kamate, C., Blazquez, S., Tefit, M., et al. Supplementation with gliadin-combined plant superoxide dismutase extract promotes antioxidant defences and protects against oxidative stress. Phytother. Res. 2004, 18, 957-62.

Vouldoukis, I., Lacan, D., Kamate, C., Coste, P., Calenda, A., Mazier, D., et al. Antioxidant and anti-inflammatory properties of a Cucumis melo LC extract rich in superoxide dismutase activity. J. Ethnopharmacol. 2004, 94, 67-75.

Wagner, A. H., Kohler, T., Ruckschloss, U., Just, I., Hecker, M. Improvement of nitric oxidedependent vasodilatation by HMGCoA reductase inhibitor through attenuation of endothelial superoxide anion formation. Arterioscler. Thromb. Vasc. Biol. 2000, 20, 619.

Wallace, D.C. Mitochondrial diseases in man and mouse. Science 1999, 283, 1482-8.

Wallstrom, P., Wirfalt, E., Lahmann, P.H., Gullberg, B., Janzon, L., et al. Serum concentrations of beta-carotene and alpha-tocopherol are associated with diet, smoking, and general and central adiposity. Am. J. Clin. Nutr. 2001, 73, 777-85.

Wang, Z., Luo, D. Antioxidant activities of different fractions of polysaccharide from Gynostemma pentaphyllum Makino. Carbohyd. Polym. 2007, 68, 54-8.

Webb, C.B., Lehman, T.L., McCord, K.W. Effects of an oral superoxide dismutase enzyme supplementation on indices of oxidative stress, proviral load, and CD4:CD8 ratios in asymptomatic FIV-infected cats. J. Feline Med. Surg. 2008, 10, 423-30. 
Wolfram, S., Raederstorff, D., Wang, Y., Teixera, S.R. et al. TEAVIGO (Epigallocatechin Gallate) supplementation prevents obesity in rodents by reducing adipose tissue mass. Ann. Nutr. Metab. 2005, 49, 54-63.

Xu, F.P., Chen, M.S., Wang, Y.Z., Yi, Q., et al. Leptin induces hypertrophy via endothelin-1reactive oxygen species pathway in cultured neonatal rat cardiomyocytes. Circulation 2004, 110, 1269-75.

Yamauchi, T., Kamon, J., Waki, H., Terauchi, Y., et al. The fat derived hormone adiponectin reverses insulin resistance associated with both lipoatrophy and obesity. Nat. Med. 2001, 7, 941-46.

Yang, B., Wang, J., Zhao, M., Liu, Y., Wang, W., Jiang, Y. Identification of polysaccharides from pericarp tissues of litchi (Litchi chinensis Sonn.) fruit in relation to their antioxidant activities. Carbohyd. Res. 2006, 341, 634-8.

Youn, S.K., Kim, Y.J., Ahn, D.H. Antioxidative effects of chitosan in meat sausage. J. Korean Soc. Food Sci. Nutr. 2001, 30, 477-81.

Young, J.F., Nielsen, S.E., Haraldsdottir, J., Daneshvar, B., Lauridsen, S. T., Knuthsen, P., et al. Effect of fruit juice intake on urinary quercetin excretion and biomarkers of antioxidative status. Am. J. Clin. Nutr. 1999, 69, 87-94. 


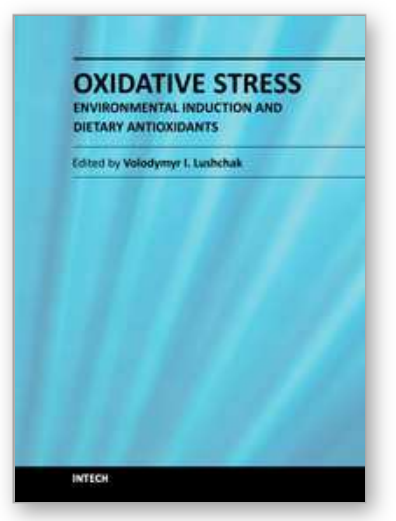

\section{Oxidative Stress - Environmental Induction and Dietary Antioxidants}

Edited by Dr. Volodymyr Lushchak

ISBN 978-953-51-0553-4

Hard cover, 388 pages

Publisher InTech

Published online 02, May, 2012

Published in print edition May, 2012

This book focuses on the numerous applications of oxidative stress theory in effects of environmental factors on biological systems. The topics reviewed cover induction of oxidative stress by physical, chemical, and biological factors in humans, animals, plants and fungi. The physical factors include temperature, light and exercise. Chemical induction is related to metal ions and pesticides, whereas the biological one highlights hostpathogen interaction and stress effects on secretory systems. Antioxidants, represented by a large range of individual compounds and their mixtures of natural origin and those chemically synthesized to prevent or fix negative effects of reactive species are also described in the book. This volume will be a useful source of information on induction and effects of oxidative stress on living organisms for graduate and postgraduate students, researchers, physicians, and environmentalists.

\section{How to reference}

In order to correctly reference this scholarly work, feel free to copy and paste the following:

Sylvie Gaillet, Dominique La and Jean-Max Rouanet (2012). Dietary Antioxidants: From Micronutrients and Phytochemicals to Enzymes - Preventive Effects on Early Atherosclerosis and Obesity, Oxidative Stress Environmental Induction and Dietary Antioxidants, Dr. Volodymyr Lushchak (Ed.), ISBN: 978-953-51-0553-4, InTech, Available from: http://www.intechopen.com/books/oxidative-stress-environmental-induction-anddietary-antioxidants/dietary-antioxidants-from-phytochemicals-to-enzymes-preventive-effects-on-earlyatherosclerosis-a

\section{INTECH}

open science | open minds

\section{InTech Europe}

University Campus STeP Ri

Slavka Krautzeka 83/A

51000 Rijeka, Croatia

Phone: +385 (51) 770447

Fax: +385 (51) 686166

www.intechopen.com

\section{InTech China}

Unit 405, Office Block, Hotel Equatorial Shanghai

No.65, Yan An Road (West), Shanghai, 200040, China

中国上海市延安西路65号上海国际贵都大饭店办公楼 405 单元

Phone: +86-21-62489820

Fax: $+86-21-62489821$ 
(C) 2012 The Author(s). Licensee IntechOpen. This is an open access article distributed under the terms of the Creative Commons Attribution 3.0 License, which permits unrestricted use, distribution, and reproduction in any medium, provided the original work is properly cited. 